\title{
NECROLÓGICAS
}

https://doi.org/10.25267/rev_atl-mediterr_prehist_arqueol_soc.2021.v23.02

\section{Enrique José Vallespí Pérez. En reconocimiento y recuerdo al querido profesor, brillante investi- gador y gran amigo}

Enrique José Vallespí Pérez nació en Fabara (Zaragoza) el 18 de julio de 1929. Murió en Sevilla el 22 de agosto de 2021.

Es para mí un deber y un gran honor escribir estas páginas de recuerdo y reconocimiento al querido profesor y amigo. Desde que tuve la fortuna, a instancias del profesor Oswaldo Arteaga Matute, de acercarme a Enrique Vallespí, en la primavera de 1982, supe que me vincularía a él en lo profesional, como maestro, y en lo humano. Enrique era un hombre excepcional, único en el trato humano, educado, respetuoso, tolerante, pero al mismo tiempo firme y sólido en sus convicciones e ideas.

No he intentado construir un análisis hagiográfico, en la línea de los trabajos publicados bajo el impacto emocional de su pérdida, pero sí me parecía necesario recordar, para las jóvenes generaciones de estudiosos, sus grandes líneas de trabajo, sus aportaciones a la Prehistoria peninsular y dejar constancia de algunos de sus trabajos publicados.

Tuve la suerte de formarme con él y aprender industrias líticas talladas paleolíticas y de la Prehistoria Reciente, pero sobre todo fui un privilegiado al compartir su amistad, sus reflexiones y su gran humanidad. Esto me permitió conocer su trayectoria y pensamiento, que a grandes rasgos quiero recordar aquí. El desarrollo de su producción bibliográfica en el contexto de la época y sus aportaciones a la Prehistoria peninsular exigirían un trabajo más profundo. Se puede consultar una magnífica Dedicatoria, realizada por el profesor Oswaldo Arteaga, con motivo de la Jubilación de Enrique Vallespí en Spal 10, donde se computa un detenido registro de su producción científica y docente (Arteaga, 2000). Es muy recomendable también la entrevista realizada por Enrique Baquedano a Enrique Vallespí, en el Museo Arqueológico Regional de Madrid, para un acercamiento a su figura y obra: Parte 1 (https://www.youtube.com/ watch?v=akwMKNZ-pZw) y Parte 2 (https://www.youtube.com/watch?v=9EC2J7UF2QE).

Enrique Vallespí desde muy joven tuvo dos grandes vocaciones, la arqueología y la docencia. Una figura clave en su vida fue su abuelo, Lorenzo Pérez Temprado. Enrique Vallespí hablaba con gran respeto de él. Recordaba al grupo del Boletín de Historia y Geografía del Bajo Aragón, formado por Santiago Vidiella Jasá, Lorenzo Pérez Temprado, Mariano Galindo García, Matías Pallarés Gil, Bernardo Gerona Ferrer, Julián Ejerique Ruiz y Juan Cabré Aguiló, con reconocimiento y admiración (Figura 1). Y de Pedro Bosch Gimpera, recordando las excavaciones en Mazaleón, donde su abuelo fue un fiel colaborador de Bosch (Vallespí, 1957a, 2010: 253 y ss.), o las de Pérez Temprado en Azaila con Juan Cabré, así como sus trabajos de campo en la zona de Fabara y Caspe, en las comarcas del Matarraña y la Terra Alta (Arteaga et al., 1990: 23-25; Cabré, 1929; Vallespí, 2001a, 2010: 370 y ss.).

Enrique Vallespí siempre habló con respeto, reconocimiento y cariño de Pedro Bosch, con quien mantuvo correspondencia (Vallespí, 2010: 462 y 463). Conservó en sus sucesivos desplazamientos por universidades españolas la documentación de planchas fotográficas, cartas de su abuelo con numerosos investigadores, apuntes, diarios, separatas y tiradas aparte de trabajos de este grupo de investigadores de la Arqueología del Bajo Aragón y de los vínculos que le unían con el Institut d'Estudis Catalans y con la importante figura de Pedro Bosch (Bosch, 1914, 1920a, 1920b, 1923, 1931, 1932).

Enrique Vallespí, conocía de primera mano, por los testimonios documentales conservados por él, de su abuelo, Pérez Temprado, en la correspondencia con Santiago Vidiella y con Juan Cabré, los primeros descubrimientos del arte rupestre del Calapatá, como dedicación del grupo del Boletín y el particular empeño pionero de Juan Cabré, en el estudio de estas manifestaciones artísticas, posteriormente integradas en el denominado arte levantino (Vidiella, 1907; Breuil y Cabré, 1909; Cabré, 1915; Vallespí, 1957d, 2006a, 2010: 236 y ss. Ver también: Ripoll, 1994; Blánquez y González, 2004).

Enrique Vallespí sabía perfectamente el carácter local-regional del grupo del Boletín. Hablaba con pasión de las excavaciones en Mazaleón, Cretas, de los trabajos de arte prehistórico en Calaceite. Era conocedor del carácter pionero de estos estudios y de su dimensión local, describiendo la dificultad y realidad sociológica, en una España de gran analfabetismo y dificultades de finales del siglo XIX y principios del XX, de una pequeña clase media culta, interesada en una renovación cultural, en clave de su afición a la Historia y a la Arqueología, y en el marco de una vocación docente y de transmisión del conocimiento aprendido. También explicaba el avance cualitativo que representó la investigación de Pedro Bosch y de su equipo del Institut d'Estudis Catalans, en directa colaboración con los miembros del 


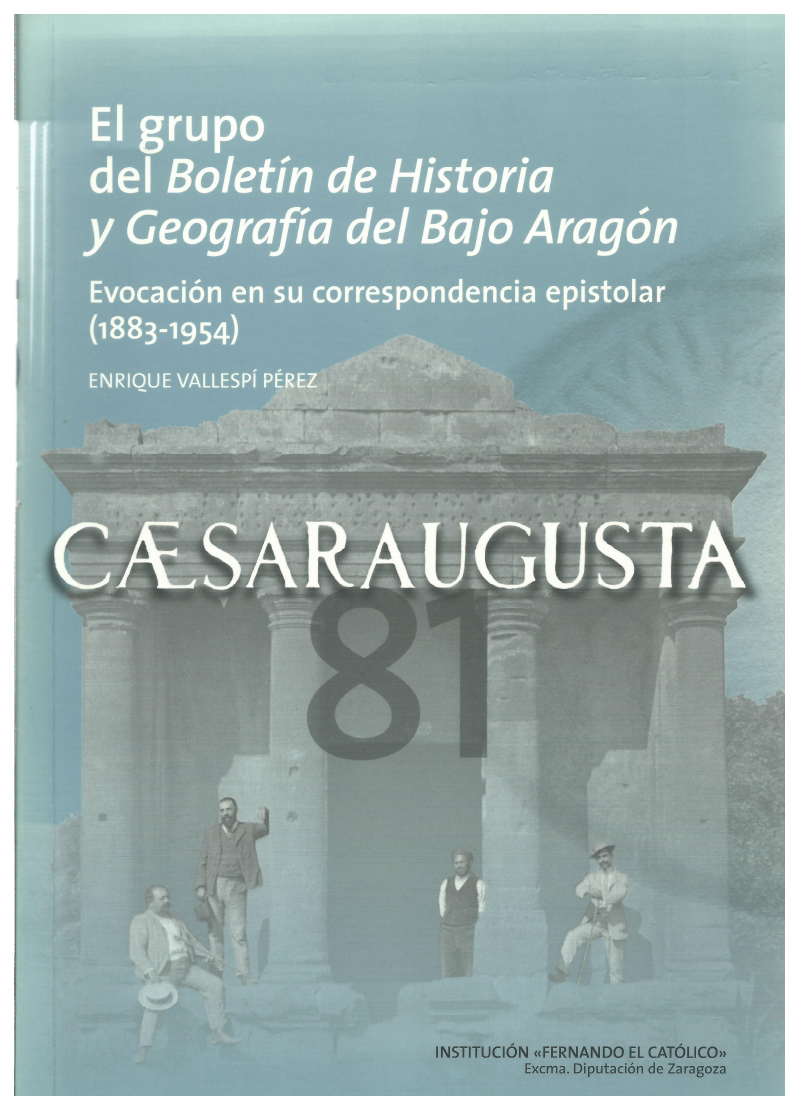

Figura 1. Portada del libro de Enrique Vallespí: El grupo del Boletín de Historia y Geografía del Bajo Aragón... Caesaragusta 81. Institución Fernando El Católico. Excma. Diputación de Zaragoza. Zaragoza, 2010.

grupo del Boletín (Vallespí, 2010: 253 y ss.; Arteaga et al., 1990: 23-25).

Esta etapa formativa de juventud fue clave en su vida profesional. De este modo desarrolló unos primeros acercamientos al arte rupestre de la zona de Monleón (Pérez Temprado y Vallespí, 1954), los primeros estudios de conjuntos líticos (Vallespí, 1953) siguiendo la senda de su abuelo y de sus compañeros del grupo del Boletín..., pero ya abriendo camino en estos trabajos, como joven investigador en la misma comarca, realizando ya un estudio de reconocimiento de series de poblados y asentamientos con lugares de producción lítica (Vallespí, 1957a, 1957b, 1957c, 1958a, 1958b, 1960a). Realmente su contribución era la de un profesional, valorando la labor de los investigadores pioneros, considerando la perspectiva de aficionados de aquellos, pero destacando su interés y el comienzo de esta línea de estudios arqueológicos (Vallespí, 2010).

Enrique Vallespí estudió Magisterio (1948), obtuvo el título de Bachiller (1952) y realizó después estudios de Filosofía y Letras, Sección de Historia (1956) en la Universidad de Zaragoza. Su Tesis Doctoral la dirigió Antonio Beltrán Martínez, defendida en enero de 1959, titulada Bases arqueológicas para el estudio de los talleres de sílex del Bajo Aragón. Obtuvo la máxima calificación. Consistió en la ordenación de la secuencia y el poblamiento prehistórico de la cuenca del Ebro, a través del análisis de la tecnología lítica tallada.

Enrique Vallespí publicó cuatro trabajos que sintetizaban aspectos fundamentales de la misma:

Un balance del estado de la cuestión del Paleolítico en el Bajo Aragón, vino a sentar la ausencia en aquellos momentos de productos vinculados a Paleolítico Inferior. Señaló un posible sustrato "de tipos musteroides (hallazgos de superficie de Els Secans)" e indicaba un "fondo industrial paleolítico superior" (Vallespí, 1961a: 61-63) de la industria lítica de Botiquería dels Moros y una atribución epipaleolítica a los conjuntos de Botiquería, Serdá y La Piñera (Vallespí, 1961a).

El peso sustancial de la tesis lo expuso en un trabajo donde exponía la por él llamada "extensa red de estaciones talleres..." que él vinculaba a las etapas entonces denominada Eneolítico y a la Edad del Bronce (Vallespí, 1959).

Revista Atlántica-Mediterránea de Prehistoria y Arqueología Social 23, pp. 12-31 Universidad de Cádiz 


\section{NECROLÓGICAS}

Presentó una síntesis de las industrias postpaleolíticas del cuadrante nordeste peninsular, analizando especialmente las del Bajo Aragón, de Araico-Treviño y de la zona de Tarragona (Vallespí, 1961b).

Y un estudio del sustrato poblacional prehistórico de la Edad del Bronce ante las ocupaciones posteriores protohistóricas, entonces denominadas de inmigrantes hallstátticos. Frente a modelos de dominación de los segundos, planteaba una hipótesis de convivencia de los grupos hallstátticos con el poblamiento indígena (Vallespí, 1961c: 246).

Enrique Vallespí precisará posteriormente "que las llamadas, con más o menos rigor metodológico, estaciones-talleres de sílex al aire libre casi en su totalidad son simplemente una de las variadas manifestaciones arqueológicas de la Edad del Bronce de la Depresión del Ebro y Cataluña mediterránea, es decir, que forman parte de un amplio poblamiento humano que en el Eneolítico o Bronce I se asienta en estas regiones geográficas y se convierte en un definitivo poblamiento estable, el Bronce indígena..." (Vallespí y Moya, 1973: 64). Sobre esta temática volvería posteriormente al valorar un tema también muy querido por él, como era el de la perduración de la talla del sílex hasta momentos avanzados de la Protohistoria, en la Edad del Hierro (Vallespí, 1986a).

Hay que considerar la obra y su contexto, en las circunstancias del país en aquellos años, y en el ámbito del predominio de modelos histórico-culturales normativos en las explicaciones y las formas de hacer arqueología (Triguer, 1989; Díaz Andreu, 2002; Moro, 2007). En este sentido hay que entender las explicaciones, incuestionadas en los años 50-60 del siglo pasado en España, como las visiones difusionistas sobre el Campiñoide, de autores como Juan Maluquer de Motes (Maluquer, 1954) o Salvador Vilaseca Anguera (Vilaseca, 1953). Con todo, sus referencias a trabajos de Bosch, y su simpatía por las ideas de Miquel Tarradell Mateu de una visión regional y con diversos focos de las culturas del Bronce, especialmente de El Argar (Tarradell, 1946, 1950; Vallespí, 1961b: 70), muestran su amplitud de ideas en aquel contexto histórico.

Enrique Vallespí, fue profesor encargado de curso entre los cursos 1956-1957 y 1957-1958, profesor Ayudante de clases prácticas en el curso 1958-1959 y profesor Ayudante de Cátedra entre los cursos 1959-1960 y 1962-1963 en la Universidad de Zaragoza, manteniendo su producción arqueológica, ya centrada en las industrias líticas prehistóricas (Arteaga, 2000:14).

Fue fundamental en su vida el encuentro con Ignacio Barandiarán Maeztu (Alday y Cava, 2007-2008). Él lo explica muy bien, dado que lo consideraba su "maestro", habiendo sido discípulo. Este tipo de reflexiones forman parte de su grandeza humana e intelectual (Vallespí, 2007-2008: 76). Su obra da un giro considerable a partir de ese momento, y la influencia de Ignacio Barandiarán se notará en su renovación didáctica docente, y especialmente en la implicación y estudio de los modelos analíticos y estructurales, de procedencia de autores como Georges Laplace (Laplace, 1964, 1966, 1972, 1974, 19851987). Enrique Vallespí no aplicaría directamente en sus estudios esta metodología, pero soy testigo de su transmisión didáctica y docente. Personalmente me facilitó las "grilles", de Laplace, disponibles en aquel momento, desde el comienzo de mis estudios de doctorado con él en la Universidad de Sevilla. Igualmente estaba al día y compartía los avances estructurales del Sistema Lógico Analítico -SLA-, de Eudald Carbonell Roura, de quien también sentía gran respeto y consideración, personal y de su obra (Carbonell et al., 1982, 1983, 1985).

Estas aplicaciones las desarrolló en su etapa de profesor en Vitoria, entre los cursos 1965-1966 y 1968-1969, sede en aquellos años de la Universidad de Deusto. Entre los cursos de 1969-1970 y 19741975 desarrolló su labor docente en la Universidad de Navarra, pudiendo ya impartir docencia en la asignatura de Prehistoria Universal.

En esta etapa, en ambas universidades consolidó su vocación docente y de investigación en las líneas fundamentales de su juventud, centrando su labor en prospecciones y estudios territoriales, con gran interés por el análisis de conjuntos líticos de superficie de Navarra, País Vasco meridional y La Rioja (Vallespí, 1960b, 1966, 1967, 1968, 1972a, 1973, 1974a, 1974b; Vallespí y Ruiz de Gaona, 1971), continuando la línea de estudios sobre el sustrato prehistórico de las ocupaciones protohistóricas (Vallespí, 1972b) y una especial atención a los estudios historiográficos, con recopilación de la historia de la investigación de Álava (Vallespí, 1966, 1967, 1970, 1972b) y de Navarra (Vallespí, 1974a, 1974b, 1975).

Esta importante dedicación, con balance historiográfico, trabajos de campo, revisión de colecciones en Museos, pudo concretarla en una de sus grandes obras, realizada junto a Ignacio Barandiarán, sobre la Prehistoria de Navarra (Barandiarán y Vallespí, 1984) (Figura 2). 
Su etapa docente en la Universidad de Oviedo (1975-1976 y 1976-1977) ya como profesor Adjunto, primero interino y definitivamente consolidado como Adjunto Titular, no fue solo de transición en su carrera académica, hasta su destino definitivo en la Universidad de Sevilla. Allí generó importantes vínculos con otros profesores e investigadores que también le influyeron y con los que mantuvo relación durante el resto de su vida, como fueron, especialmente Javier Fortea Pérez, y con un joven Manuel González Morales.

Enrique Vallespí se incorpora a la Universidad de Sevilla en el curso 1977-1978, como Profesor Adjunto-Titular de Prehistoria y su dedicación docente e investigadora va a suponer un gran revulsivo en la dinamización de los estudios prehistóricos, orientado sobre todo a la formación de nuevos investigadores y al estudio de conjuntos e industrias líticas paleolíticas y de la Prehistoria Reciente del sur peninsular.

En la Universidad de Sevilla, conectará con todos los profesores, debido a su carácter integrador y afable, vinculando un afecto especial a los profesores Oswaldo Arteaga Matute y Pilar Acosta Martínez, que compartieron asignatura de Prehistoria de Andalucía, durante muchos años con él. Con Oswaldo Arteaga le unía además su vinculación e interés común por los estudios del Bronce y Prehistoria Reciente del Bajo Aragón, dado que el profesor Arteaga trabajó en el territorio inspeccionado por su abuelo, siendo gran conocedor del sustrato local protohistórico del Bajo Aragón (Arteaga, 1977; Arteaga et al., 1990). En la monografía de Tossal del Moro de Pinyeres se hace justicia a la labor de trabajo de campo de Lorenzo Pérez Temprado, del grupo del Boletín y de los propios estudios de Enrique Vallespí en el Roquizal o Tossal del Moro (Arteaga et al., 1990: 31 y ss.).

En su etapa de investigación en la Universidad de Sevilla colabora con los jóvenes investigadores y profesores del Departamento de Prehistoria y Arqueología, realizando trabajos en Extremadura con Víctor Hurtado Pérez, sobre los conjuntos líticos del asentamiento de La Pijotilla (Badajoz) (Vallespí et al., 1985a). También trabaja en Ciudad Real, con Antonio Ciudad Serrano sobre conjuntos líticos del

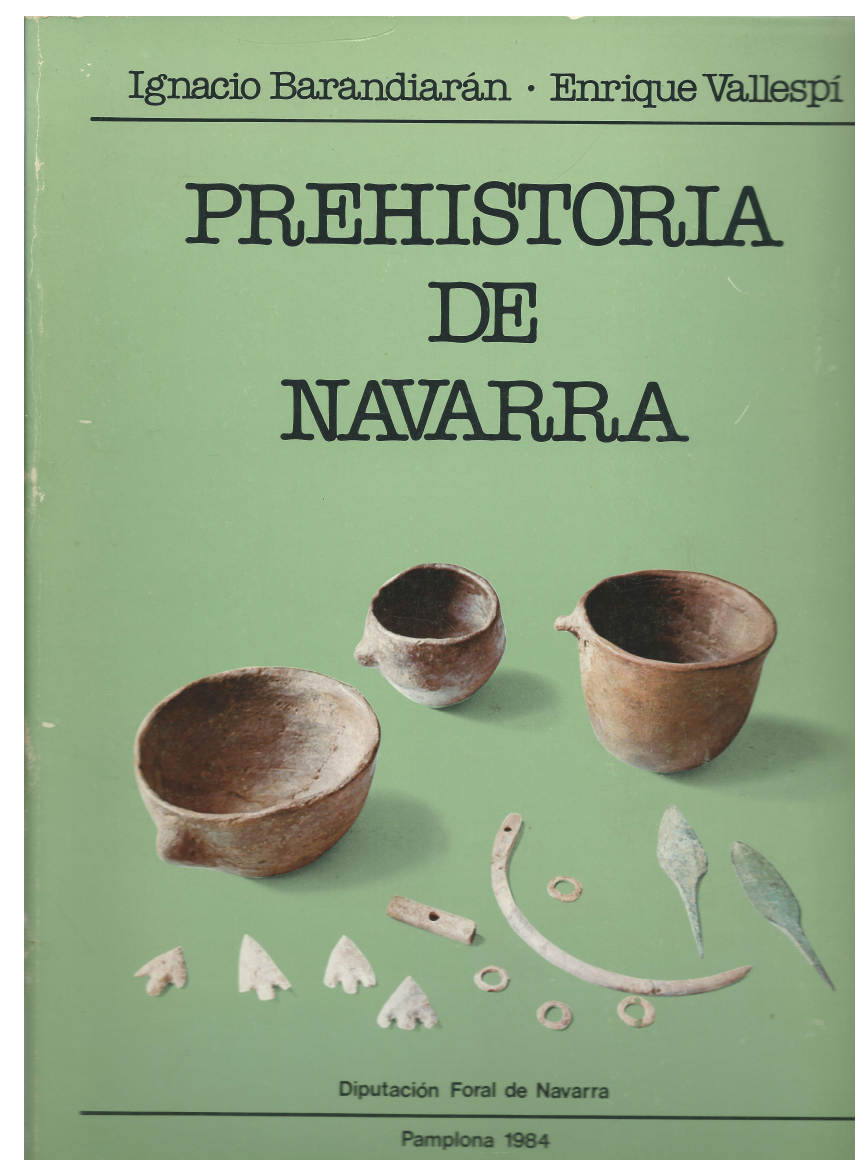

Figura 2. . Portada del libro de Ignacio Barandiarán y Enrique Vallespí: Prehistoria de Navarra. Diputación Foral de Navarra. Pamplona, 1984. 


\section{NECROLÓGICAS}

Neolítico y Prehistoria Reciente (Vallespí et al., 1985b), así como de conjuntos líticos de la Prehistoria Reciente de la Mesa de Ocaña en Toledo (Vallespí et al., 1989a) y sobre los muy interesantes yacimientos en terrazas fluviales pleistocenas del río Bullaque, en la cuenca del Guadiana, de Porzuna en Ciudad Real (Vallespí et al., 1979, 1985c, 1988a) (Figura 3), o Alto Vélez en Málaga (Vallespí et al., 1989b).

Consideramos de gran interés historiográfico la apertura de una línea de estudios de tecnología lítica tallada de la Prehistoria Reciente en el sur peninsular, que inició con la publicación de los productos líticos tallados de Montecorto (Vallespí y Cabrero, 1980-1981) y otros talleres de la zona del Guadalteba y Axarquía de Málaga (Vallespí et al., 1988b, 1988c), de Huelva (Castiñeira et al., 1988; Ramos et al., 1988), así como de las sierras de Cádiz (Ramos et al., 1993). En dicha línea me incorporé personalmente con el estudio de manifestaciones similares del Alto Vélez, en la Axarquía de Málaga (Ramos, 1988) (Figura 4) y a otras zonas de Andalucía (Ramos, 1995). A dicha temática se unieron posteriormente Pedro Cantalejo Duarte, María del Mar Espejo Herrerías y Emilio Martín Córdoba, a estudios de lugares de producción lítica de sociedades de la Prehistoria Reciente en el sur peninsular (Ramos et al., 1986; Ramos y Martín, 1987). Destacar también que, desde la Universidad de Sevilla, tanto Enrique Vallespí (Figuras 5 y 6), como Oswaldo Arteaga, apoyaron firmemente, nuestros estudios y trabajos en Cueva de Ardales (Málaga) (Ramos et al., 1992; Cantalejo et al., 1997, 2005).

Desde el Departamento de Prehistoria y Arqueología de la Universidad de Sevilla, a partir de 1977, desarrolló una importante línea de trabajos y proyectos de investigación centrados en la secuencia de ocupación de la cuenca del río Guadalquivir con estudios geoarqueológicos de terrazas fluviales, análisis tecnológicos y valoración de los poblamientos humanos (Vallespí, 1986b, 1986c, 1987, 1992, 1994, 1999, 2006b), muchos de estos trabajos en colaboración con Fernando Díaz del Olmo y su equipo de geógrafos (Díaz del Olmo y Vallespí, 1988; Díaz del Olmo et al., 1986; Vallespí y Díaz del Olmo, 1996). En una importante síntesis indica el objetivo de este proyecto:

"Un ejemplo regional importante lo constituye, en efecto, el estudio que presentamos del Paleolítico del Bajo Guadalquivir, con sobrado interés para que la interpretación de su remoto po-

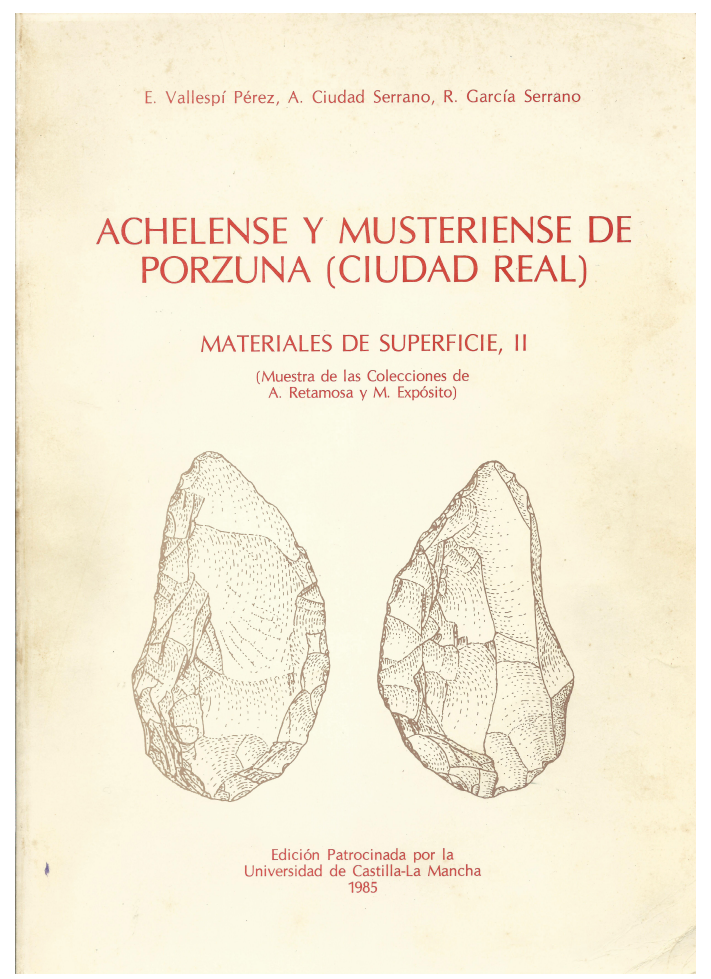

Figura 3. Portada del libro de Enrique Vallespí, Antonio Ciudad y Rafael García: Achelense y Musteriense de Porzuna (Ciudad Real). Materiales de superficie, II. Universidad de Castilla-La Mancha, Ciudad Real, 1985. 
blamiento inicial implicado en su secuencia geoarqueológica pueda ser considerada desde las perspectivas mentales que proponemos, puesto que la amplitud cronológica y la continuidad de registros paleolíticos ininterrumpidos en los depósitos de los ocho niveles de aterrazado fluvial, desde el Pleistoceno Medio inicial al Superior Antiguo, constituye el modelo regional del proceso achelense del Sur peninsular y resulta imprescindible para el planteamiento de una secuencia general estándar del Paleolítico Inferior de la totalidad de la Península Ibérica, avalado su interés, además, por su vinculación geográfica al Magreb africano" (Vallespí, 2006b: 1410-1411).

Un gran colaborador y prospector del proyecto fue Genaro Álvarez García. El ámbito geográfico del mismo abarcó territorialmente desde el Genil al litoral atlántico, analizando las industrias líticas en conexión estratigráfica en los perfiles de terrazas fluviales. Se enmarcaron los primeros trabajos en un Proyecto del Ministerio de Educación y Ciencia, a partir de 1980-1981, contando con la codirección de Fernando Díaz del Olmo (Díaz del Olmo et al., 1986). En este marco organizaron en Sevilla la V Reunión del Grupo Español de Trabajo del Cuaternario, (Vallespí et al., 1982), así como varias reuniones en los años sucesivos del Grupo Andaluz de Cuaternario de AEQUA (Rodríguez Vidal et al., 1988).

Procedentes de los resultados del proyecto se generaron las tesis doctorales de Rafael Baena Escudero, Juan José Fernández Caro y José Antonio Caro Gómez, que han producido numerosas publicaciones (por ejemplo: Baena y Díaz del Olmo, 1994; Fernández, 2000; Caro, 2006).

Trabajador incansable, publicó numerosos artículos, informes, contribuciones a congresos en el marco de las sucesivas campañas de prospección y estudio desarrolladas, encuadradas dentro de las pertinentes autorizaciones de la Junta de Andalucía en la cuenca del río Guadalquivir (Vallespí et al., 1982, 1988d; Díaz del Olmo y Vallespí, 1987, 1988; Díaz del Olmo et al., 1989, 1990, 1992a, 1992b). Queremos destacar también algunas síntesis importantes, como su valoración del Paleolítico Inferior y Medio del sur peninsular, en el Homenaje a Luis Siret (1934-1984), dando una verdadera visión histórica de los

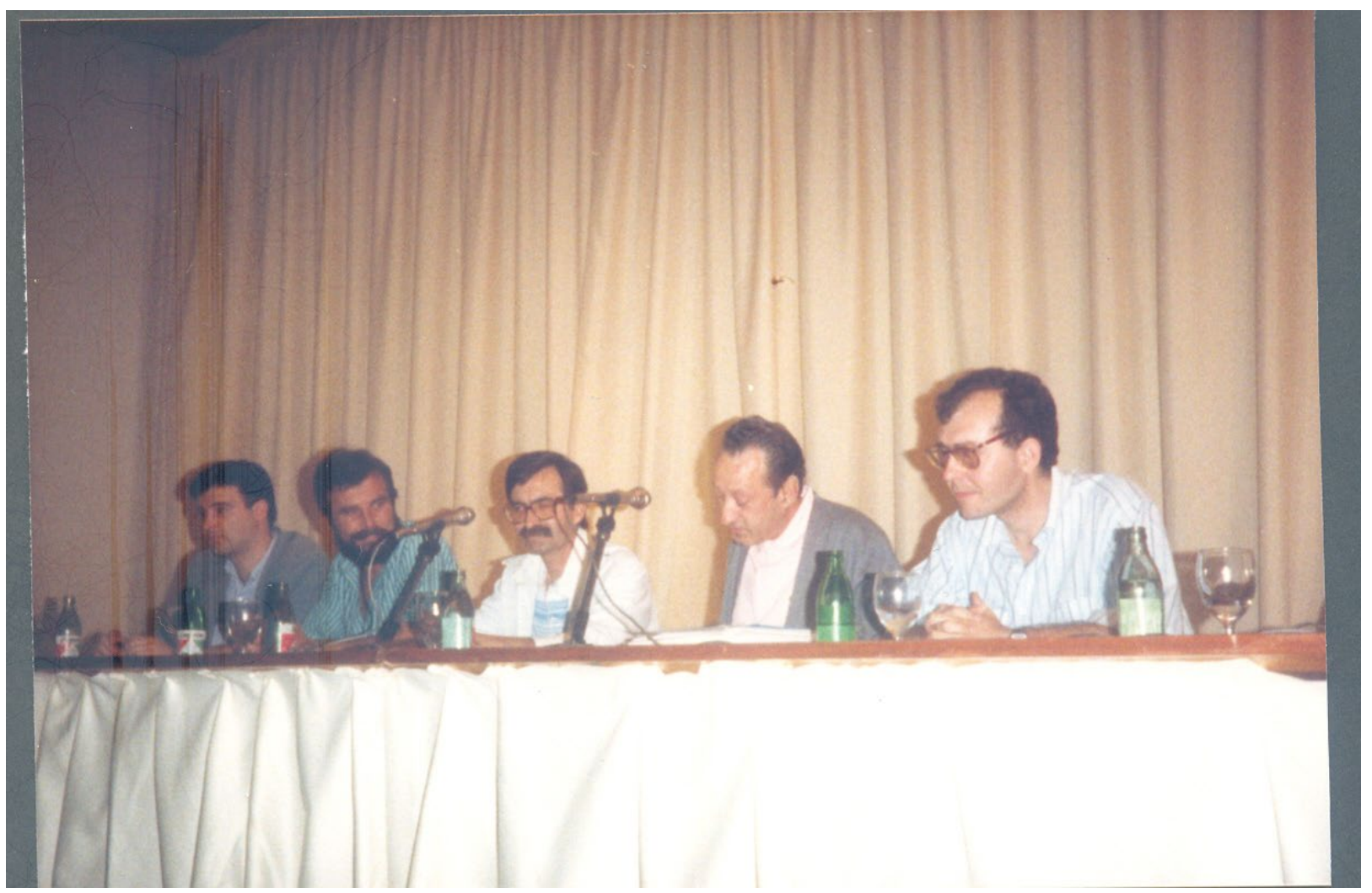

Figura 4. Presentación del libro de José Ramos y Emilio Martín: Tajo de Gomer..., en el Instituto de Enseñanza Secundaria Reyes Católicos de Vélez-Málaga (Málaga). Junio de 1987. De izquierda a derecha: Emilio Martín, Ángel Recio, Salvador Soriano, Enrique Vallespí y José Ramos. 


\section{NECROLÓGICAS}

comienzos del poblamiento humano en Andalucía hasta el Paleolítico Medio (Vallespí, 1986b); su valoración del Paleolítico Inferior inicial de la península ibérica, con integración de los contextos arqueológicos, documentados hasta ese momento en el sur peninsular (Vallespí, 1986c, 1987, 1995, 2001), sus trabajos sobre las industrias achelenses (Vallespí, 1992; Vallespí et al., 2007), o las denominadas por él, industrias postachelenses, situadas en "la perduración achelense con...un complejo mixtificado de esa perduración y el impacto, en tipos y técnica, musteriense, como facies local no clásica del Paleolítico Medio" (Vallespí, 2006: 1418; 1988) y visiones generales de la secuencia paleolítica de las terrazas fluviales del río Guadalquivir (Díaz del Olmo y Vallespí, 1988; Vallespí, 1994, 1999, 2001; Vallespí et al., 2001) o su interés y reflexión sobre la primera ocupación del espacio local de Sevilla (Vallespí, 1983, 1985a).

Hay que destacar su visión elaborada en las últimas síntesis, donde expone la estratigrafía de la secuencia y los niveles de las terrazas, considerando las terrazas muy altas, T1 a T4 en el Pleistoceno Inferior, las T5 a T9 en el Pleistoceno Medio y T10 a T13 en Pleistoceno Superior. El trabajo fue ingente, con la documentación en el río Guadalquivir de más de 45 yacimientos, y 30 localizaciones con industrias en conexión estratigráfica; así como más de 200 localizaciones en el río Corbones (Vallespí, 2006: 1416 y ss, Vallespí et al., 2007).

Indicar también que en paralelo a la fijación de la gran secuencia paleolítica del río Guadalquivir dinamizó y animó a la continuidad de numerosos estudios paleolíticos en diferentes comarcas de Andalucía, generando un impulso y estímulo de otros proyectos y equipos de investigación, como el desarrollado por otro buen amigo de Enrique, como es Francisco Giles Pacheco, y su grupo de investigación del Museo Municipal de El Puerto de Santa María (Giles et al., 1989, 1996). Igualmente señalar los trabajos desarrollados junto a José Castiñeira Sánchez y José María García Rincón en Huelva (Vallespí et al., 1981, 1986), o los realizados por nuestro grupo de investigación de la Universidad de Cádiz, en la banda atlántica litoral de Cádiz (Ramos coord., 2008), así como los indicados trabajos en Cueva de Ardales, con Pedro Cantalejo Duarte, María del Mar Espejo Herrerías y José Ramos Muñoz (Ramos et al., 1992; Cantalejo et al., 1997, 2005) (Figura 6).

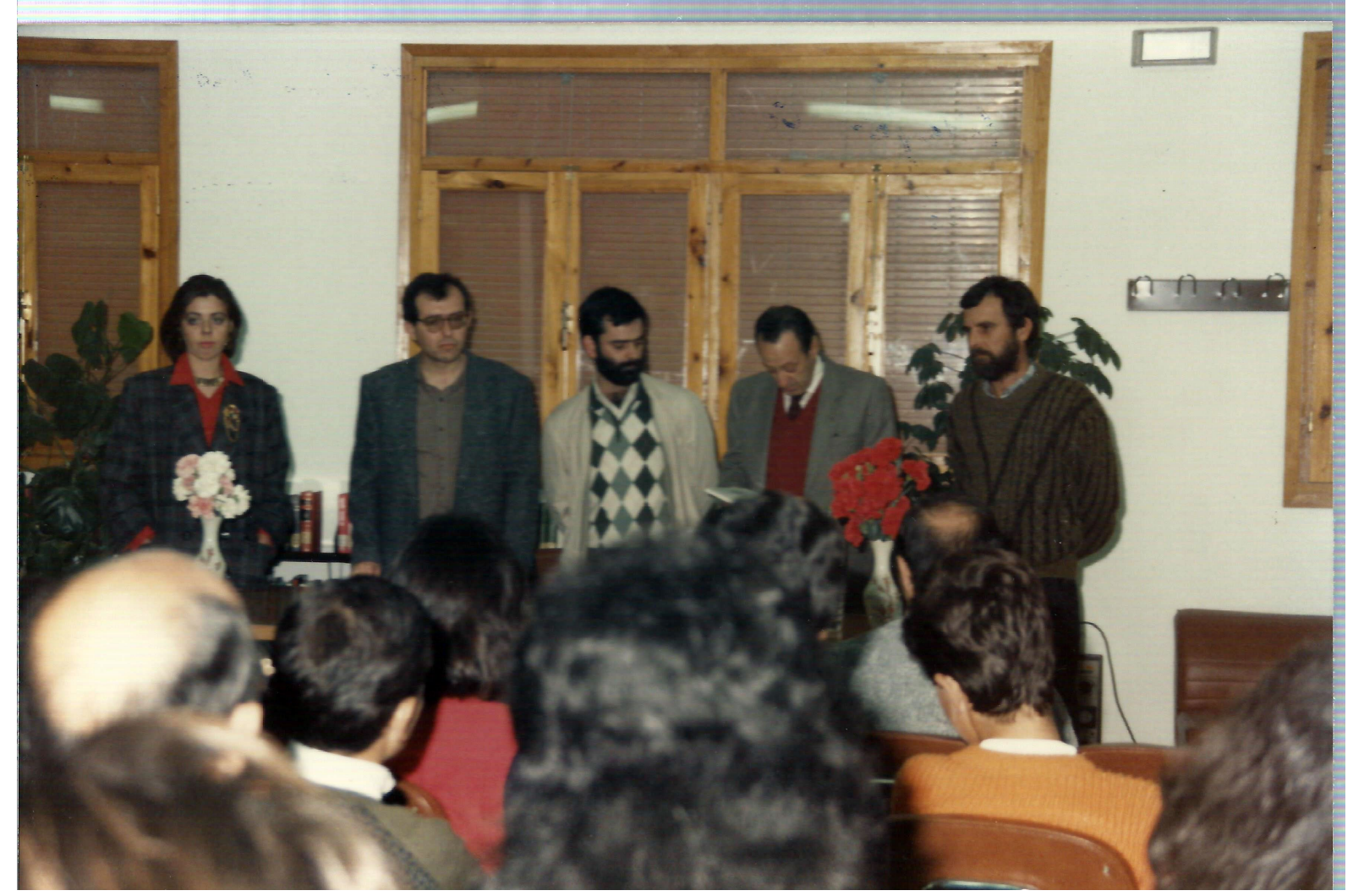

Figura 5. Presentación del libro de José Ramos, Mar Espejo y Pedro Cantalejo: Taller calcolítico del Castillo del Turón, en la Biblioteca Municipal de Ardales. 1987. De izquierda a derecha: Mar Espejo, José Ramos, Manuel Jiménez, Enrique Vallespí y Ángel Recio. 


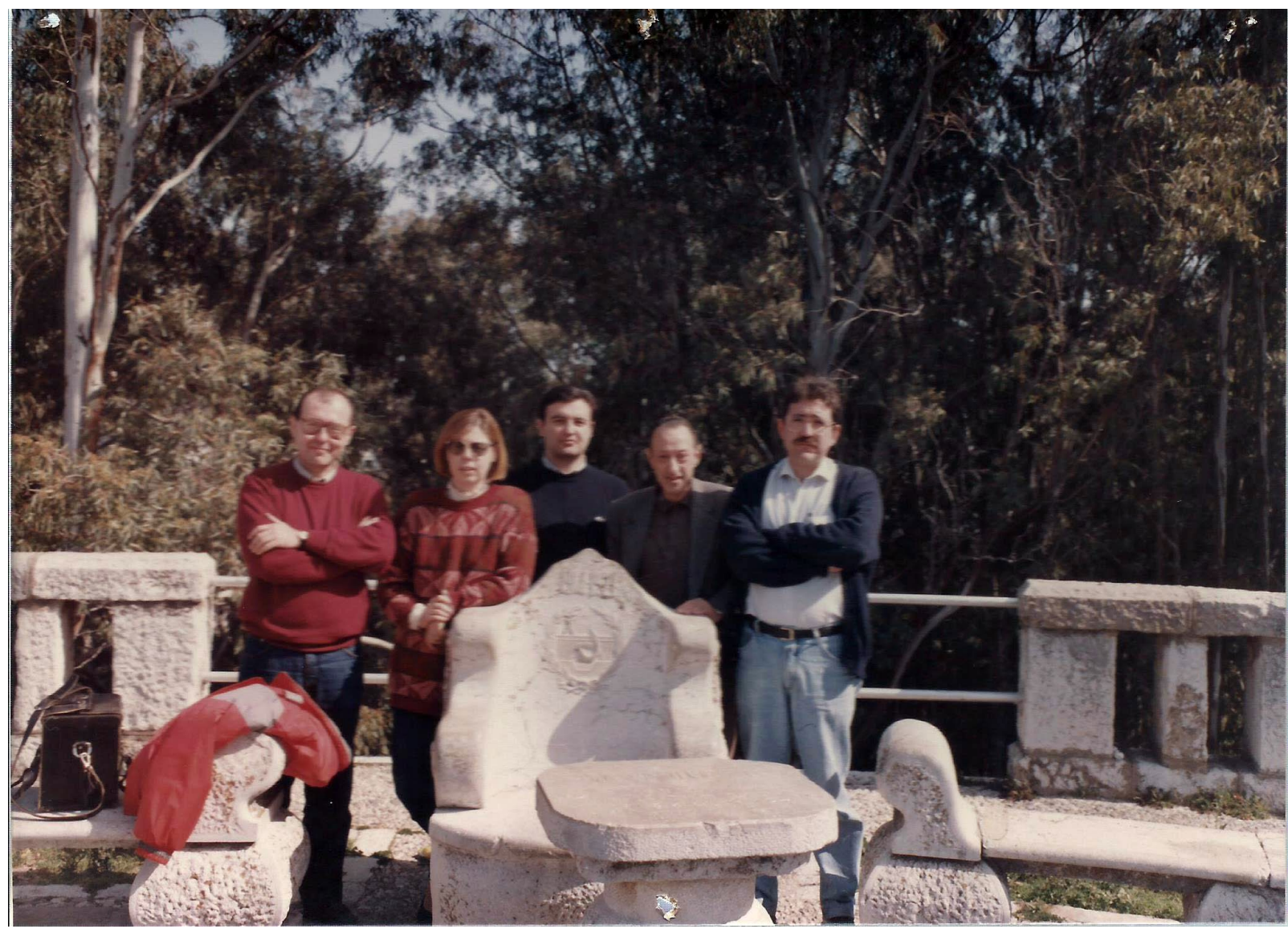

Figura 6. Visita a los embalses de Ardales, con motivo de la presentación del libro: Cueva de Ardales. Su recuperación y estudio 1992. De izquierda a derecha: José Ramos, Mar Espejo, Enrique Vallespí, Emilio Martín y Pedro Cantalejo.

Señalar también la presentación de numerosos productos líticos paleolíticos en varias comarcas de Andalucía, con el fin de dinamizar en los grupos locales la continuidad de los estudios, como en el alto Guadalete en Cádiz (Vallespí et al., 1983-1984); Subbético de Sevilla (Vallespí, 1985b) Alto Guadalquivir en Jaén (Vallespí et al., 1992), Bajo Genil en Cordoba (Vallespí, 1993), o Alto Vélez en Málaga (Vallespí et al., 1989b).

La valoración docente de su actividad ha sido reconocida ampliamente por sus discípulos y compañeros (Ver algunos testimonios en Arteaga, 2000; Díaz del Olmo, 2021; Sánchez, 2021; Garrido, 2021). Su magisterio en la formación de especialista la avalaba una larga trayectoria en la dirección de trabajos de investigación. Indicamos así que en la Universidad de Navarra, había dirigido las Memorias de Licenciatura de María Amor Beguiristain Gúrpide (1972), María Inés Tabar Sarrías (1973), Juan Cruz Labeaga Mendiola (1973), Alberto Monreal Jimeno (1974), G. Ortego (1975) (Arteaga, 2000: 15).

En la Universidad de Sevilla, en el Departamento de Prehistoria y Arqueología (Arteaga, 2000: 15-16; https://dialnet.unirioja.es/servlet/autor?codigo=60010), dirigió las Memorias de Licenciatura de Caridad Espín Cánovas (1985), José Castiñeira Sánchez (1987), María Teresa Murillo Díaz (1987), José Antonio Caro Gómez (1996) y las Tesis Doctorales de: Antonio Ciudad Serrano (1985), José Ramos Muñoz (1986), Rafael Baena Escudero (1993), Emilio Martín Córdoba (1995), José Juan Fernández Caro (1998) y José Antonio Caro Gómez (1999) (Arteaga, 2000: 16-17).

A lo largo de su vida profesional perteneció a numerosas comisiones científicas asesoras de organismos públicos, destacando: Comisión Organizadora de las Semanas de Antropología Vasca (1970-1973), Comisión de Excavaciones y Arqueología de la Institución Príncipe de Viana de Navarra (1973-1975); Seminario Permanente de Historia de Andalucía (1981-1983), Jurado de la Beca de Investigación José Miguel de Barandiarán (1982 y 1986), Coordinador Científico del Coloquio sobre el hombre de Orce (1983), Comisión Asesora de Arqueología, Paleontología y Etnografía de Castilla-La Mancha (1986-

Revista Atlántica-Mediterránea de Prehistoria y Arqueología Social 23, pp. 12-31

Universidad de Cádiz 


\section{NECROLÓGICAS}

1987), Jurado Calificador del Concurso de monografías "Archivo Hispalense" (1983-1985), Comisión Asesora de Arqueología Andaluza de la Junta de Andalucía (1985-1991) (http://tierra.rediris.es/aequa/ arquero.html), así como Miembro de la Comisión Asesora Internacional para la Depresión de Guadix-Baza, de la Consejería de Cultura de la Junta de Andalucía (1997-1999). Igualmente fue miembro de numerosos comités científicos de congresos (Figura 7), como el I Simposio de Prehistoria Cueva de Nerja, en homenaje al profesor Dr. D. Francisco Jordá Cerda (1996) y de comités editoriales (Arteaga, 2000: 17-19).

Destacamos algunas distinciones, como el Premio Arquero de Oro de AEQUA en las VIII Reunión del Cuaternario Ibérico celebrado en Sevilla-La Rinconada, en octubre de 2013 (http://tierra.rediris.es/ aequa/arquero.html).

Nuestro grupo de investigación vinculado con los proyectos desarrollados en Ardales (Málaga) (Espejo y Cantalejo, 2005) tuvo la satisfacción de rendirle un merecido homenaje el 11 de noviembre de 2005, en Ardales (Málaga), en el marco de las Primeras Jornadas de Patrimonio en la Comarca del Guadalteba (Málaga) (Figuras 8 a 12).

Queremos destacar también especialmente el Volumen dedicado por la Revista Spal, en el número 9 (2000), con motivo de su jubilación, que contó con una emotiva y profunda Dedicatoria resaltando sus valores intelectuales y humanos, así como su trayectoria, realizada por su buen amigo y compañero, el profesor Oswaldo Arteaga, de la Universidad de Sevilla (Arteaga, 2000).

Quiero destacar en su larga trayectoria la presencia de algunos temas y aportaciones importantes:

- La Historiografía. Era conocedor por el legado de su abuelo de la génesis de la Prehistoria de Aragón y del vínculo con Pedro Bosch. De este modo transmitía con claridad la noción de las diferentes visiones que le tocó vivir, entre el "Pueblo Hispánico", predominante en su época (Almagro, 1958) y "La Prehistoria de los pueblos de España" heredada de la influencia de Bosch en la figura y recuerdos familiares (Bosch y Aguado, 1945; Bosch, 1923, 1974; Comas 1976; Ripoll, 1984). Él sabía transmitir con un respeto y reconocimiento la historia de la investigación, en su manera de ver la vida, abierta y tolerante.

- La ordenación del poblamiento paleolítico del bajo Aragón, destacando un sustrato que veía en la

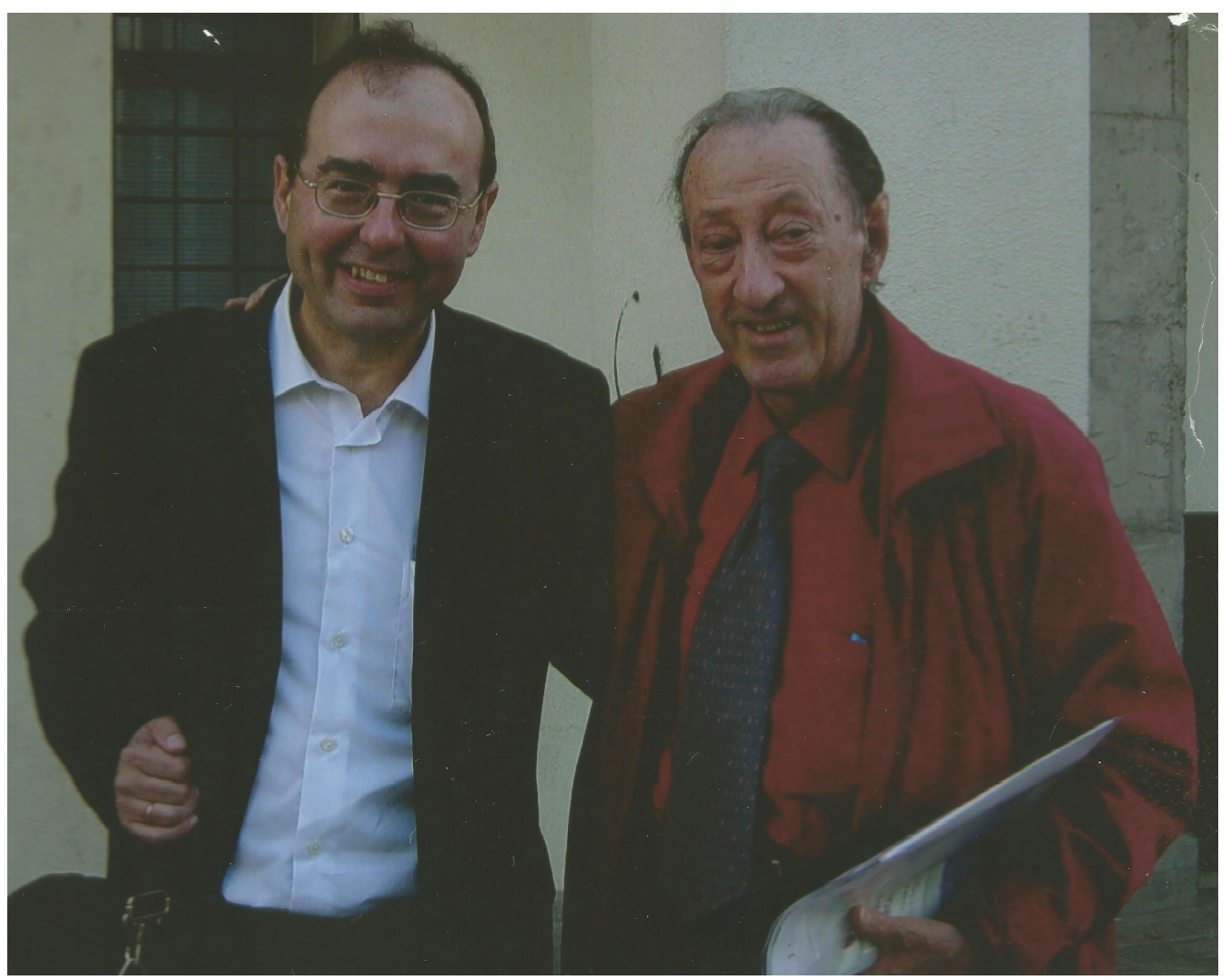

Figura 7. VI Edición del Seminario "Francisco Sousa". La Rinconada, Sevilla: Enrique Vallespí y José Ramos. 6 de noviembre de 2004. 
tipología, del poblamiento posterior Epipaleolítico (Vallespí, 1959, 1961a).

- La fijación territorial de la ocupación de la Prehistoria Reciente, a partir de los estudios de conjuntos y estaciones líticas, patrones de asentamiento y organización de poblados, lugares de producción (por él llamados talleres) y analizar el sustrato poblacional prehistórico de las poblaciones protohistóricas en el cuadrante noreste peninsular (Vallespí, 1959, 1961b, 1986a).

- Importante labor de prospecciones y aportaciones al poblamiento del cuadrante noreste de la Península ibérica, especialmente con interés por el estudio de lugares con tecnología lítica de la Prehistoria Reciente, Neolítico, Eneolítico, en denominación de la época- y posteriores de La Rioja (Vallespí, 1960b, 1973; Vallespí y Moya, 1973), Álava (Vallespí, 1966, 1967, 1968, 1970, 1972b) y Navarra (Vallespí, 1974a, 1974b, 1975).

- Gran síntesis e importante obra de alcance en la conformación de la visión histórica de la "Prehistoria de Navarra", en coautoría con su gran compañero y amigo, Ignacio Barandiarán (Barandiarán y Vallespí, 1984).

- Estudios regionales en Extremadura, de la tecnología lítica de los poblados del IIIer. milenio a.n.e. (Vallespí et al., 1985a).

- Estudio de terrazas pleistocenas y material paleolítico asociado de la cuenca del Guadiana en la provincia de Ciudad Real (Vallespí et al., 1979, 1985c, 1988a).

- Apertura de una línea de estudios de tecnología lítica tallada de la Prehistoria Reciente en el sur peninsular (Vallespí y Cabrero, 1980-1981; Vallespí et al., 1988b, 1988c).

- En su etapa andaluza, organización de la secuencia paleolítica del Guadalquivir, con gran preocupación estratigráfica de la sucesión pleistocena y organización de la tecnología achelense y musteriense (1986b, 1986c, 1987, 1992, 1994, 1999).

- Dinamización y apoyo a grupos de investigadores y a los estudios paleolíticos en Andalucía.

- Renovación metodológica en el sur peninsular, al introducir la lógica analítica de Georges Laplace y el Sistema Lógico Analítico de Eudald Carbonell, que el profesor Vallespí transmitió en su docencia doctoral, alcanzando su magisterio, una gran aplicación a numerosos conjuntos paleolíticos y de la Prehistoria Reciente de Andalucía y norte de África.

Para finalizar quiero indicar que Enrique Vallespí, ha sido para mí desde que tuve la suerte de acercarme a él para iniciar mis estudios de doctorado en la Universidad de Sevilla, mucho más que un maestro. Enrique ha sido un gran amigo, una persona entrañable, juiciosa, de gran coherencia personal y un ejemplo de actitud ética. Hemos compartido ilusiones que desbordan ampliamente los estudios prehistóricos. Siempre me demostró un elevado sentido de la justicia, respeto por las ideas y opiniones ajenas y gran tolerancia. Lo recordaremos siempre.

\section{Referencias bibliográficas}

ALDAY RUIZ, Alfonso; CAVA ALMUZARA, Ana. 2007-2008: “Ignacio Barandiarán Maestu: una experiencia didáctica e investigadora de la Prehistoria". Veleia, 24-25, pp. 33-75.

ALMAGRO BASCH, Martín. 1958: Origen y formación del pueblo hispano. Vergara. Barcelona.

ARTEAGA MATUTE, Oswaldo. 2000: “Dedicatoria”. Spal, 9. Homenaje al Profesor Vallespí, pp. 9-28.

ARTEAGA MATUTE, Oswaldo. 1977: "Problemas de la penetración céltica por el Pirineo Occidental (ensayo de aproximación)”. XIV Congreso Arqueológico Nacional, pp. 549-564. Zaragoza.

ARTEAGA MATUTE, Oswaldo; PADRÓ I PARCERISA, Josep; SANMARTÍ GREGO, Enric. 1990: El poblado ibérico del Tossal del Moro de Pinyeres (Batea, Terra Alta, Tarragona). Institut de Prehistoria i Arqueología. Monografies Arqueològiques 7. Diputació de Barcelona. Barcelona.

BAENA ESCUDERO, Rafael; DÍAZ DEL OLMO, Fernando. 1994: “Cuaternario aluvial de la depresión del Guadalquivir: episodios geomorfológicos y cronología paleomagnética". Geogaceta, 15, pp. 102-103.

BLÁNQUEZ PÉREZ, Juan; GONZÁLEZ REYERO, Susana. 2004: “D. Juan Cabré Aguiló. Comentarios oportunos a una biografía inacabada”. En J. BLÁNQUEZ y S. GONZÁLEZ (eds.): El arqueólogo Juan Cabré (18821947). La fotografía como técnica documental, pp. 19-42. Instituto Patrimonio Histórico Español. Universidad Autónoma de Madrid, Museo de San Isidro. Madrid.

BOSCH GIMPERA, Pedro. 1914: “Campanya arqueológica del Institut d'Estudis Catalans al limit de Catalunya i Aragó (Caseres, Calaceite y Massalió”. Anuari del Institut d'Estudis Catalans, V, 1913-1914, pp. 819-838.

Revista Atlántica-Mediterránea de Prehistoria y Arqueología Social 23, pp. 12-31

Universidad de Cádiz 


\section{NECROLÓGICAS}

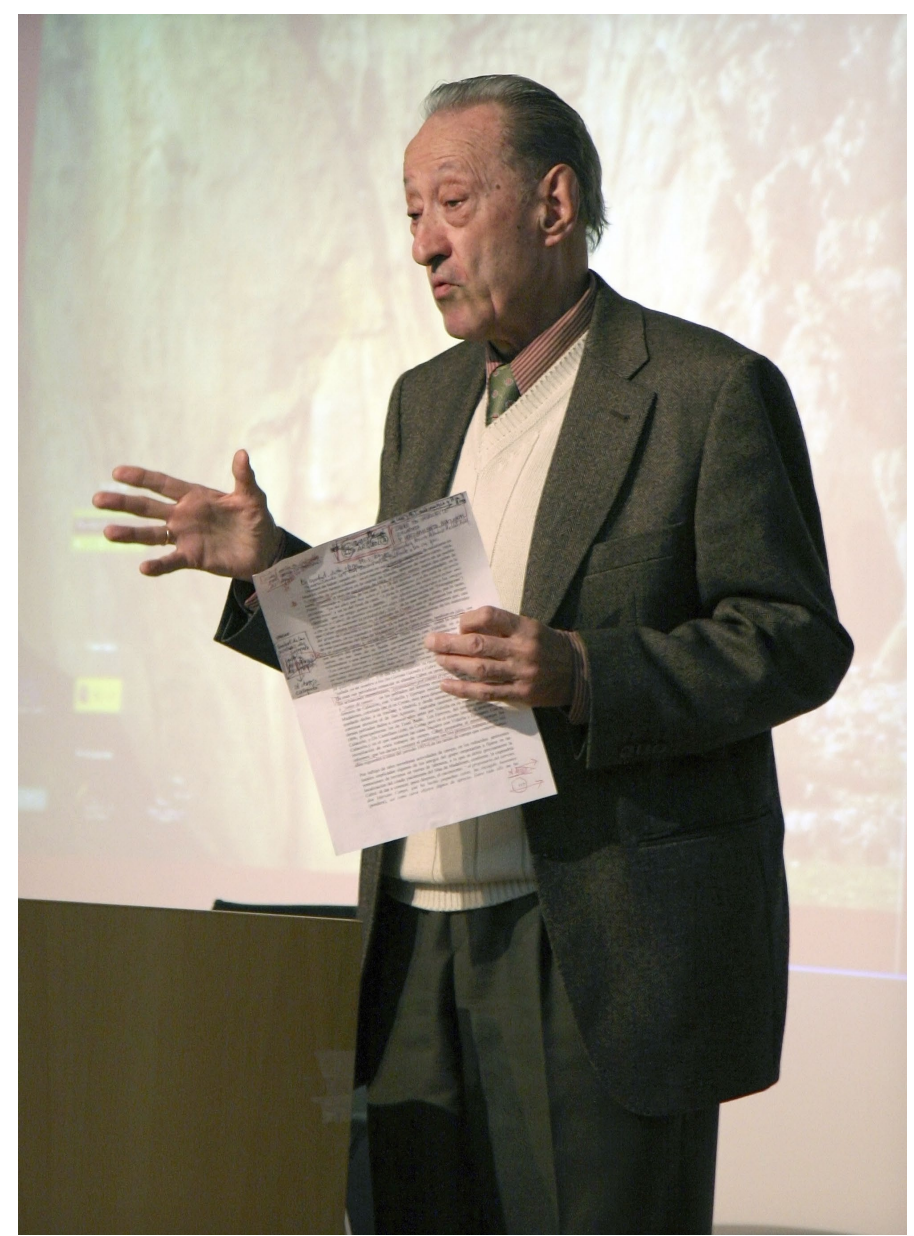

Figura 8. Conferencia inaugural de Enrique Vallespí, de las Primeras Jornadas de Patrimonio en la comarca del Guadalteba (Ardales, Málaga), 11 de noviembre de 2005.

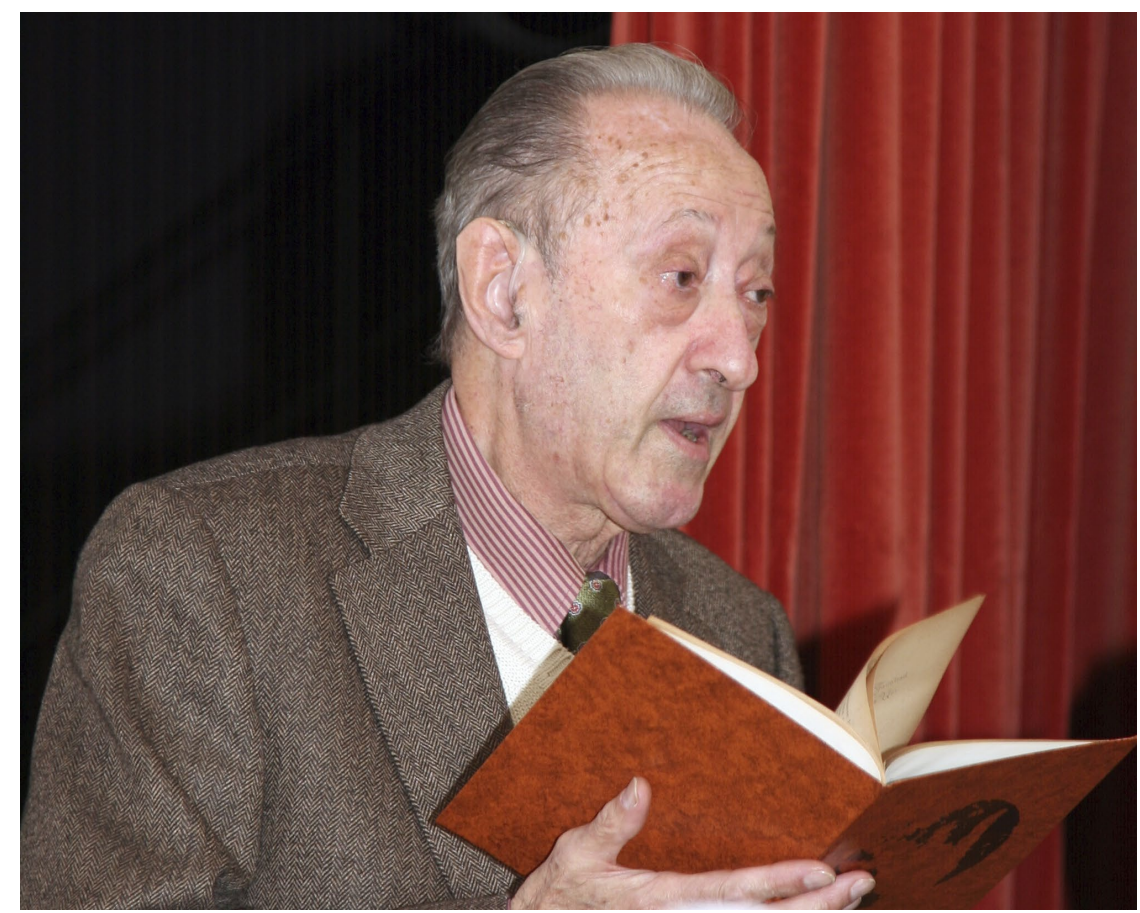

Figura 9. Enrique Vallespí con original del trabajo de Henri Breuil sobre la Cueva de Ardales. Conferencia Primeras Jornadas de Patrimonio en la comarca del Guadalteba (Ardales, Málaga), 11 de noviembre de 2005. 
BOSCH GIMPERA, Pedro. 1920a: "Les estacions eneolítiques del Baix Aragó i del regne de Valencia". Anuari del Institut d'Estudis Catalans, VI, 1915-1920, pp. 7-8.

BOSCH GIMPERA, Pedro. 1920b: "Les investigaciones de la cultura ibérica al Baix Aragó". Anuari del Institut d'Estudis Catalans, VI, 1915-1920, pp. 641-671.

BOSCH GIMPERA, Pedro. 1923: "Notas de Prehistòria aragonesa”. Butlletí de la Associació Catalana d'Antropología, Etnología y Prehistòria, I, pp. 15-68.

BOSCH GIMPERA, Pedro. 1931: "Les investigaciones de la cultura ibérica al Baix Aragó”. Anuari de l'Institut d'Estudis Catalans, VII, 1921-1926, pp.72-78.

BOSCH GIMPERA, Pedro. 1932: Etnología de la Península Ibérica. Urgoiti Editores. Pamplona. 2003.

BOSCH GIMPERA, Pedro. 1974: La España de todos. Seminarios y ediciones. Madrid

BOSCH GIMPERA, Pedro; AGUADO BLEYE, Pedro. 1945. El poblamiento y la formación de los pueblos de España. Universidad Nacional Autónoma de México. México.

BREUIL, Henri; CABRÉ AGUILÓ, Juan. 1909: “Les peintures rupestres du bassin infèrieur de l'Ebre”. L'Anthropologie, XX, pp. 1-21.

CABRÉ AGUILÓ, Juan. 1915: El arte rupestre en España. (Regiones septentrional y oriental). Comisión de Investigaciones Paleontológicas y Prehistóricas I. Museo de Ciencias Naturales. Madrid.

CABRÉ AGUILÓ, Juan. 1929: Excavaciones en el Roquizal del Rullo, Término de Fabara, dirigidas por D. Lorenzo Pérez Temprado. Memorias de la Junta Superior de excavaciones y Antigüedades 101. Madrid. CANTALEJO DUARTE, Pedro; ESPEJO HERRERÍAS, María del Mar; RAMOS MUÑOZ, José. 1997: Cueva de Ardales. Guía del legado histórico y social. Ayuntamiento de Ardales. Málaga.

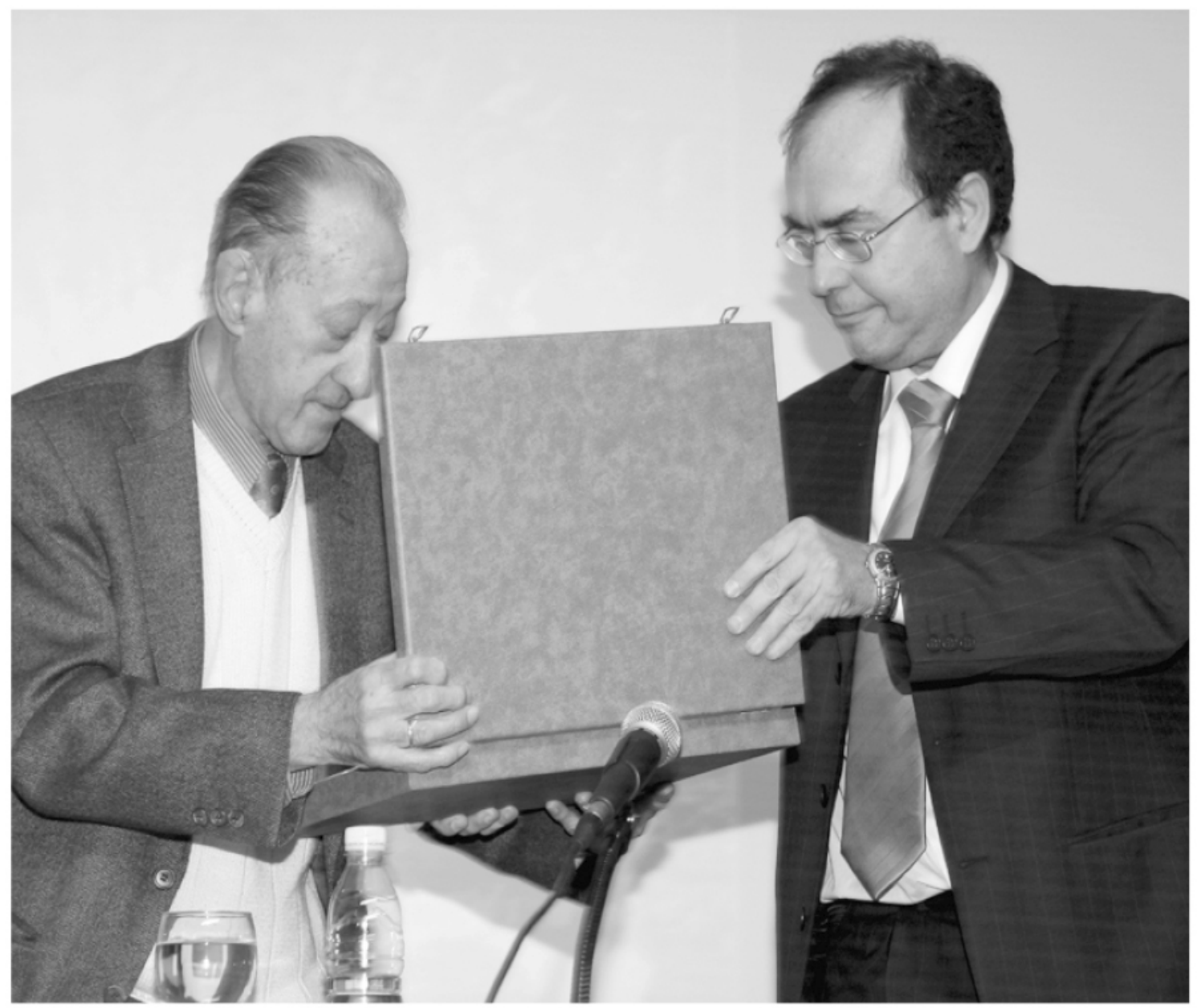

Figura 10. José Ramos hace entrega de placa de homenaje al profesor Enrique Vallespí. Ardales, 11.11.2005.

Revista Atlántica-Mediterránea de Prehistoria y Arqueología Social 23, pp. 12-31

Universidad de Cádiz 


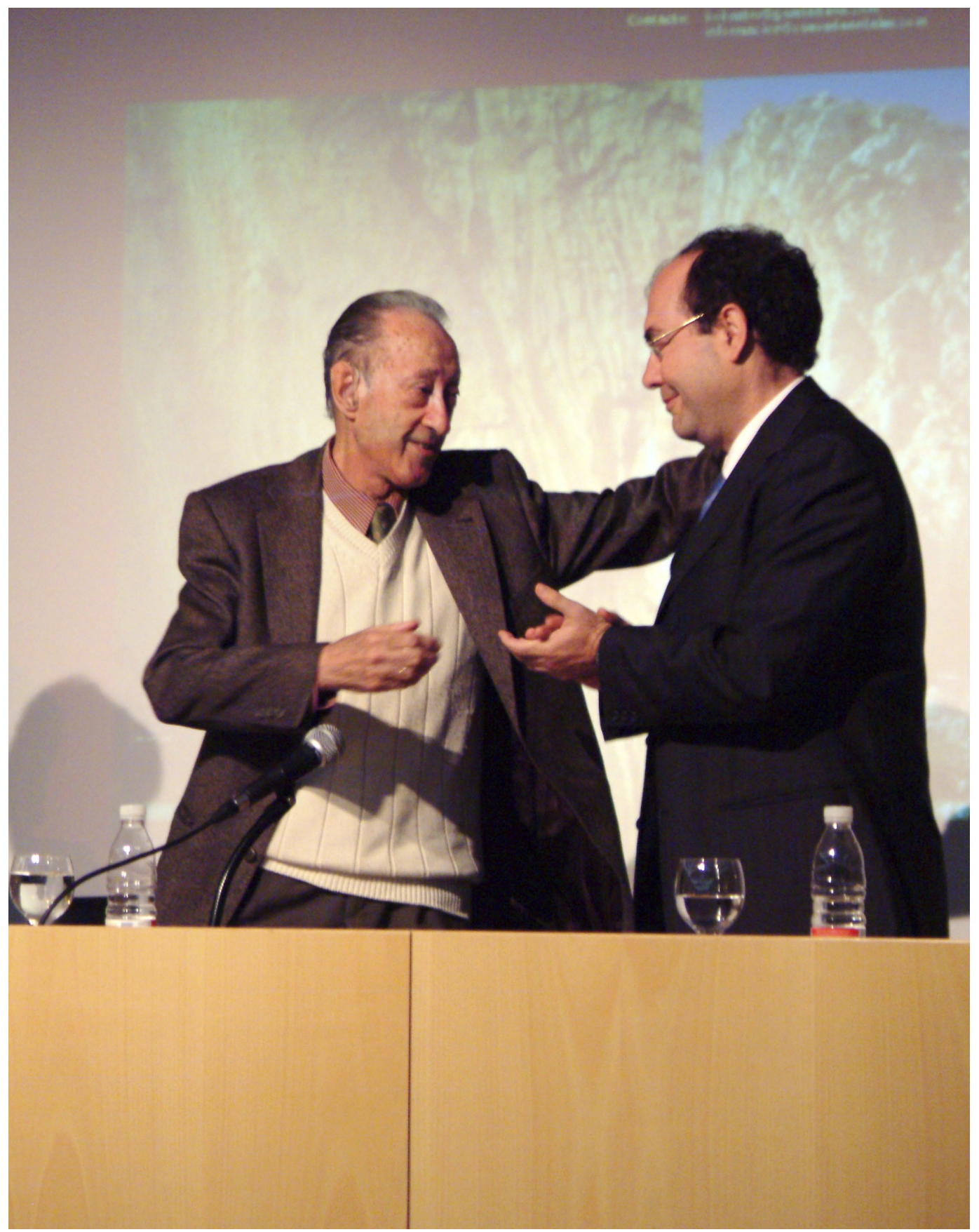

Figura 11. Enrique Vallespí en el acto de homenaje realizado en Ardales. Ardales, 11.11.2005. 


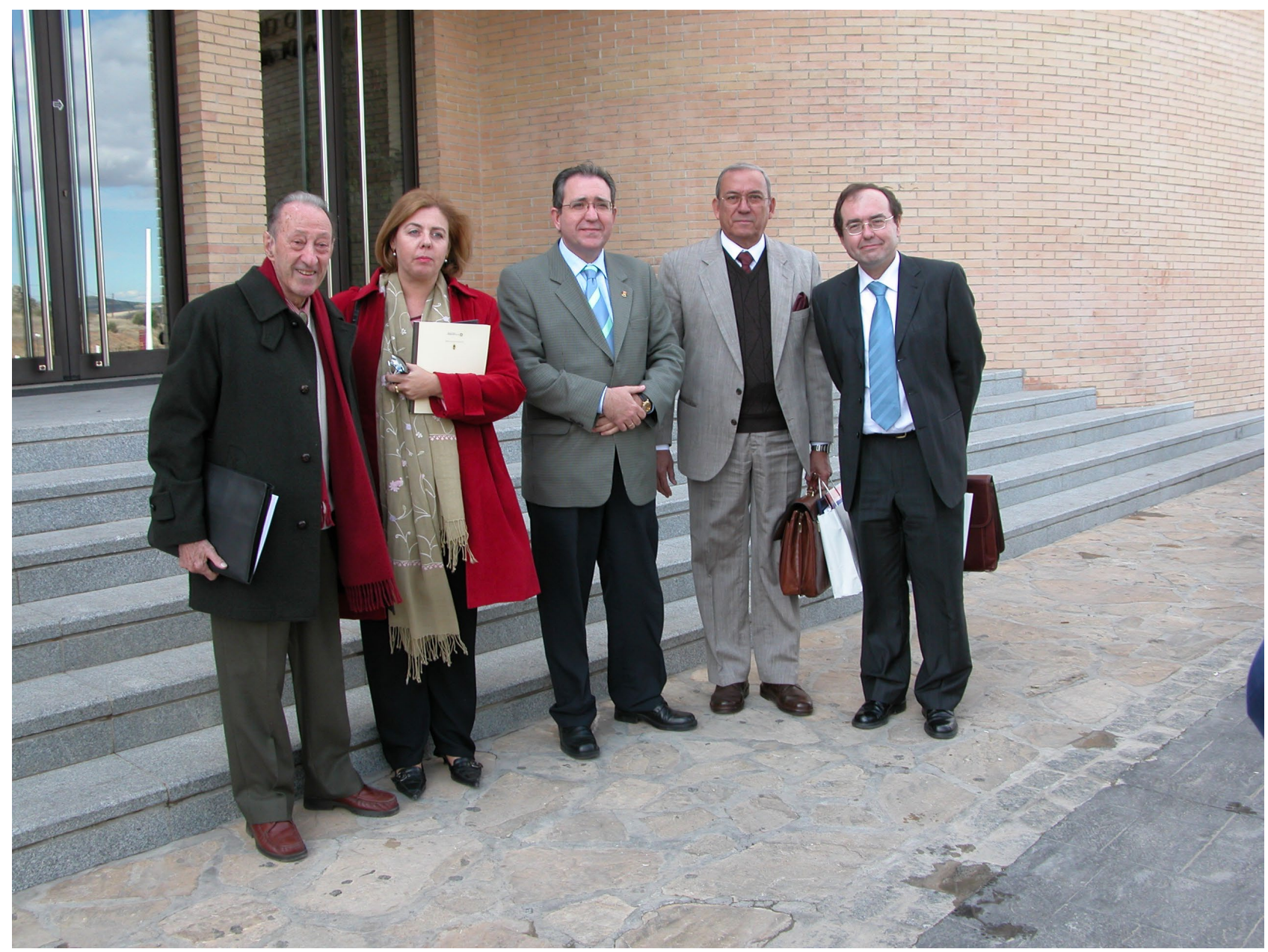

Figura 12. Primeras Jornadas de Patrimonio en la comarca del Guadalteba (Ardales, Málaga), 11 de noviembre de 2005. De izquierda a derecha: Enrique Vallespí, Mar Espejo, Pedro Cantalejo, Oswaldo Arteaga y José Ramos.

CANTALEJO DUARTE, Pedro; MAURA MIJARES, Rafael; ESPEJO HERRERÍAS, María del Mar; RAMOS MUÑOZ, José; MEDIANERO, Javier; ARANDA CRUCES, Antonio; DURÁN VALSERO, Juan José. 2005: Vestigios gráficos y evidencias de frecuentación durante el Paleolítico Superior en Cueva de Ardales (Málaga) 19852005. Servicio de Publicaciones. Centro de Ediciones de la Diputación de Málaga. Málaga.

CARBONELL ROURA, Eudald; GUILBAUD, Michel; MORA TORCAL, Rafael. 1983: “Utilización de la lógica analítica para el estudio de tecno-complejos a cantos tallados". Cahier-Noir, 1, pp. 3-64.

CARBONELL ROURA, Eudald; MORA TORCAL, Rafael. ; GUILBAUD, Michel. 1985: "Application of the logical analytical system to the Middle Paleolithic Period". Cahier Noir, 2, pp. 11-70.

CARBONELL ROURA, Eudald; GUILBAUD, Michel; MORA TORCAL, Rafael. 1982: "Application de la méthode dialectique à la construction d'un système analytique pour l'étude des materiaux du Paleolithique Inferieur". Dialektiké. Cahiers de typologie analytique, pp. 7-23.

CARO GÓMEZ, José Antonio, 2006: "Yacimientos e industrias achelenses en las terrazas fluviales de la Depresión del Bajo Guadalquivir (Andalucía, España). Secuencia estratigráfica, caracterización tecnocultural y cronología". Carel, IV, 4, pp. 1423-1605.

COMAS CAMPS, Juan. 1976: In Memoriam Pedro Bosch-Gimpera 1981-1974. UNAM. México.

DÍAZ-ANDREU, Margarita. 2002: Historia de la Arqueología. Estudios. Ediciones Clásicas. Madrid.

DÍAZ DEL OLMO, Fernando. 2021: "E. Vallespí, adiós al maestro del Paleolítico". Diario de Sevilla. $3 / 9 / 2021$.

ESPEJO HERRERÍAS, María del Mar; CANTALEJO DUARTE, Pedro. 2005: “Crónicas de las primeras Jornadas de Patrimonio en la comarca del Guadalteba (Málaga)". En P. CANTALEJO (coord.): Ias Jornadas 


\section{NECROLÓGICAS}

de Patrimonio en la Comarca del Guadalteba. Arte rupestre y sociedades prehistóricas con expresiones gráficas. Patrimonio Guadalteba. Número Especial, pp. 11-19. Asociación para la Defensa del Patrimonio Histórico y Natural de laComarca del Guadalteba. Málaga.

FERNÁNDEZ CARO, Juan José. 2000: “El Paleolítico Medio de medios fluviales: yacimientos en superficie de la cuenca del Corbones, afluente del Guadalquivir“. Spal, 9, pp. 225-244.

GARRIDO, Francisco. 2021: "Enrique Vallespí Pérez, profesor y arqueólogo". https://www.lavozdelsur. es/opinion/enrique-vallespi-perez-profesor-arqueologo 264556 102.html. 01/09/2021.

GILES PACHECO, Francisco; SANTIAGO PÉREZ, Francisco; GUTIÉRREZ LÓPEZ, José María; MATA ALMONTE, Esperanza; AGUILERA RODRÍGUEZ, Luis. 1989: "El poblamiento paleolítico en el valle del río Guadalete, Cádiz". En El Cuaternario en Andalucía Occidental. AEQUA Monografías, 1, pp. 43-57. Sevilla GILES PACHECO, Francisco; GUTIÉRREZ LÓPEZ, José María; MATA ALMONTE, Esperanza; SANTIAGO PÉREZ, Antonio. 1996: “Laguna de Medina. Bassin du fleuve Guadalete (Cadiz, Espagne). Un gisement acheuléen ancien dans le cadre des premiers occupations humaines de la péninsule Ibérique". L'Anthropologie, 100, no 4, pp. 507-528.

LAPLACE, Georges, 1966: “Pourquoi une typologie analytique?”. L'Anthropologie, 70, no 1-2, pp. 193-201. LAPLACE, Georges, 1964: "Essai de typologie systématique”. Annali dell'Universitá di Ferrara, Sezione XV, pp. 1-85.

LAPLACE, Georges, 1972: "La typologie Analytique et Structurale: Base rationnelle d'étude des industries lithiques et osseuses". Colloques Nationaux C.N.R.S. № 932. Banques de Données Archéologiques, (Marseille, 1972), pp. 91-143.

LAPLACE, Georges, 1974: "De la dynamique de l'analyse structurale ou la typologie analytique". Rivista di Szienze Preistoriche, Vol. XXIX, fasc. 1, pp. 1-71.

LAPLACE, G., 1985-1987: “Un exemple de nouvelle écriture de la grille typologique”. Dialektike, pp. 1621.

MALUQUER DE MOTES, Juan. 1954: “La industria lítica en Olazagutía”. Príncipe de Viana, LIV y LV, pp. 9-27.

MORO ABADÍA, Óscar. 2007: Arqueología prehistórica e historia de la ciencia. Hacia una historia crítica de la arqueología. Bellaterra arqueología. Barcelona.

RAMOS MUÑOZ, José. 1988: El poblamiento prehistórico del Alto Vélez hasta la Edad del Bronce. Con Prólogo de Enrique Vallespí. Diputación Provincial de Málaga, Málaga.

RAMOS MUÑOZ, José. 1995: "Talleres líticos de la prehistoria Reciente en Cádiz". En E. RIPOLL y M. LADERO (eds.): Actas del II Congreso Internacional 'El Estrecho de Gibraltar', pp. 127-149. UNED y Ayto. de Ceuta. Madrid.

RAMOS MUÑOZ, José. (coord.). 2008: La ocupación prehistórica de la campiña litoral y Banda Atlántica de Cádiz. Aproximación al estudio de las sociedades cazadoras-recolectoras, tribales-comunitarias y clasistas iniciales. Arqueología Monografías. Junta de Andalucía. Sevilla.

RAMOS MUÑOZ, José; ESPEJO HERRERÍAS, María del Mar; CANTALEJO DUARTE, Pedro. 1986: Taller calcolítico del Castillo del Turón. Ardales (Málaga). Ayuntamiento de la Villa de Ardales. Málaga.

RAMOS MUÑOZ, José; MARTÍN CÓRDOBA, Emilio. 1987: Tajo de Gomer (Riogordo, Málaga). Un asentamiento neolítico al aire libre en el Alto Vélez. Ayuntamiento de Vélez-Málaga 2, Vélez Málaga.

RAMOS MUÑOZ, José; ESPEJO HERRERÍAS, María del Mar; CANTALEJO DUARTE, Pedro; MARTÍN CóRDOBA, Emilio; MOLINA MUÑOZ, José A.; DURÁN VALSERO, Juan J.; ALCÁZAR GODOY, José; RAMÍREZ TRILlO, Federico; VELA TORRES, Antonio; GRÜN, Rainer; FORD, Derek, C. 1992: Cueva de Ardales. Su recuperación y estudio. Ayuntamiento de Ardales. Málaga

RIPOLL PERELLÓ, Eduardo. 1984: El origen de los pueblos de España. Instituto Español de Emigración. Ministerio de Trabajo y Seguridad Social. Madrid.

RIPOLL PERELLÓ, Eduardo. 1994: El Abate Henri-Breuil (1877-1961). U.N.E.D. Madrid.

SÁNCHEZ LIRANZO, Olga. 2021: "Agradecimiento a Enrique José Vallespí Pérez". https://cdlsevillayhuelva.org/agradecimiento-a-enrique-jose-vallespi-perez/. 25/08/2021.

TARRADELL MATEU, Miquel. 1946: "Sobre la delimitación geográfica de la Cultura del Argar". II Congreso Arqueológico del Sudeste Español, 4-7, pp. 139-141. Museo Arqueológico de Murcia. Murcia.

TARRADELL MATEU, Miquel. 1950: "La península ibérica en la época de El Argar". Crónica del I Congreso Nacional de Arqueología y del V Congreso Arqueológico del Sudeste. Publicaciones de la Junta Municipal 
de Arqueología y del Museo de Cartagena, pp. 72-84. Cartagena.

TRIGUER, Bruce, G. 1989: A History of Archaeological Thought. Cambridge University Press. Cambridge. VIDIELLA JASSÁ, Santiago. 1907: “Las pinturas rupestres del término de Cretas". Boletín de Historia y Geografía del Bajo Aragón, I, no 2, pp. 18-75.

VILASECA ANGUERA, Salvador. 1953: Las industrias de sílex tarraconenses. CSIC. Instituto Rodrigo Caro. Madrid.

\section{Referencias bibliográficas de Enrique Vallespí Pérez citadas en este texto}

BARANDIARÁN MAEZTU, Ignacio; VALLESPÍ PÉREZ, Enrique. 1984: Prehistoria de Navarra. Diputación Foral de Navarra. Pamplona.

CASTIÑEIRA SÁNCHEZ, José; CASTIÑEIRA PALOU, Roser; RAMOS MUÑOZ, José; VALLESPÍ PÉREZ, Enrique. 1988: "Talleres líticos del calcolítico y la Edad de Bronce en la cuenca minera de Riotinto y su relación con la minería prehistórica: el ejemplo de la Chaparrita (Nerva)". En Desde la historia hacia el futuro. Memoria: I Congreso Nacional Cuenca Minera de Riotinto: Riotinto 28, 29 y 30 de octubre de 1988, pp. 37-62- Riotinto.

DÍAZ DEL OLMO, Fernando; VALLESPÍ PÉREZ, Enrique; ÁLVAREZ GARCÍA, Genaro. 1986: "Formations superficielles détritiques et séquence paléolithique du Bas Guadalquivir (SW de l'Espagne)". Méditerranée, 3, pp. 61-65.

DÍAZ DEL OLMO, Fernando; VALLESPÍ PÉREZ, Enrique. 1987: “Formaciones cuaternarias y conexiones paleolíticas del bajo Guadalquivir (Sevilla, sector La Campana-Carmona)”. Anuario Arqueológico de Andalucía/1987. Tomo II. Actividades Sistemáticas. Informes y Memorias, pp. 29-32. Junta de Andalucía. Sevilla. DÍAZ DEL OLMO, Fernando; VALLESPÍ PÉREZ, Enrique. 1988: "Secuencia fluvial y paleolítica del Guadalquivir: terrazas y conexiones arqueológicas (Sevilla)". Trabajos de Paleolítico y Cuaternario, pp. 53-57. Universidad de Sevilla. Sevilla.

DÍAZ DEL OLMO, Fernando; VALLESPÍ PÉREZ, Enrique; BAENA ESCUDERO, Rafael; RECIO ESPEJO, José Manuel. 1989: "Terrazas pleistocenas del Guadalquivir Occidental: Geomorfología, suelos, paleosuelos y secuencia cultural". En F. DÍAZ DEL OLMO y J. RODRÍGUEZ (eds.): El Cuaternario en Andalucía Occidental, pp. 33-42. Monografías de AEQUA 1. Sevilla.

DÍAZ DEL OLMO, Fernando; VALLESPÍ PÉREZ, Enrique; BAENA ESCUDERO, Rafael. 1990: "Bajo Guadalquivir y afluentes secundarios: terrazas fluviales y secuencia paleolítica (trabajos 1990)". Anuario Arqueológico de Andalucía/1990. Tomo II. Actividades Sistemáticas. Informes y Memorias, pp. 35-39. Junta de Andalucía. Sevilla.

DÍAZ DEL OLMO, Fernando; VALLESPÍ PÉREZ, Enrique; BAENA ESCUDERO, Rafael. 1992 a: "Formaciones cuaternarias y secuencia paleolítica en el Bajo Guadalquivir". En J. CAMPOS y F. NOCETE (coords.): Investigaciones arqueológicas en Andalucía: 1985-1992. Proyectos, pp. 193-210. Consejería de Cultura y Medio Ambiente. Junta de Andalucía. Huelva.

DÍAZ DEL OLMO, Fernando; VALLESPÍ PÉREZ, Enrique; BAENA ESCUDERO, Rafael. 1992 b: "Bajo Guadalquivir y afluentes secundarios: terrazas fluviales y secuencia paleolítica (trabajos 1990)". Anuario Arqueológico de Andalucía/1990. Tomo II. Actividades Sistemáticas. Informes y Memorias, pp. 35-39. Junta de Andalucía. Sevilla.

PÉREZ TEMPRADO, Lorenzo; VALLESPÍ PÉREZ, Enrique. 1954: “Las Caídas del Salbime, Mazaleón (Teruel), nuevo yacimiento bajoaragonés con arte rupestre". Caesaraugusta Publicaciones del Seminario de Arqueología y Numismática Aragonesa, 4, pp. 31-49.

RAMOS MUÑOZ, José; VALLESPÍ PÉREZ, Enrique; PÉREZ SINDREU, Francisco de Paula. 1988: “Conjunto de sílex calcolítico de la Sierra de Aracena: (Huelva)". En Desde la historia hacia el futuro. Memoria: I Congreso Nacional Cuenca Minera de Riotinto: Riotinto 28, 29 y 30 de octubre de 1988, pp. 755-787. Riotinto. RAMOS MUÑOZ, José; VALLESPÍ PÉREZ, Enrique; ÁLVAREZ GARCÍA, Genaro. 1993. "Industria lítica calcolítica tallada en Arenisca de la Sierra de Líbar en la Serranía de Grazalema (Málaga-Cádiz)”. Gades, 21, pp. 9-36.

RODRÍGUEZ VIDAL, Fernando; MAYORAL ALFARO, Eduardo; CASTIÑEIRA SÁNCHEZ, José; GARCÍA RINCÓN, José María; DÍAZ DEL OLMO, Fernando; VALLESPÍ PÉREZ, Enrique: BAENA ESCUDERO, Rafael; ÁLVAREZ GARCÍA, Genaro; BORJA BARRERA, Francisco. 1988: Aluvionamientos cuaternarios en la depreRevista Atlántica-Mediterránea de Prehistoria y Arqueología Social 23, pp. 12-31

Universidad de Cádiz 


\section{NECROLÓGICAS}

sión del Guadalquivir. AEQUA, Grupo Andaluz del Cuaternario. Cádiz.

VALLESPÍ PÉREZ, Enrique. 1953: "Nuevos materiales para el estudio de la Arqueología aragonesa. El abrigo de La Noguera (Zabara)". Caesaraugusta. Publicaciones del Seminario de Arqueología y Numismática Aragonesa, 2, pp. 129-131.

VALLESPÍ PÉREZ, Enrique. 1957a: “Las prospecciones y excavaciones arqueológicas de D. Lorenzo Pérez Temprado (1865-1954)”. Teruel, 17-18, pp. 353-356.

VALLESPÍ PÉREZ, Enrique. 1957b: “Cerámica cardial en el Bajo Aragón”. Zephyrus, VIII-2. Pp. 275-278. VALLESPÍ PÉREZ, Enrique. 1957c: "Yacimientos líticos en el rio Matarraña”. En IV Congreso Nacional de Arqueología, pp. 68-70. Zaragoza.

VALLESPÍ PÉREZ, Enrique. 1957d: "Noticia de las pinturas rupestres del Barranco dels Gascons (Calapatá, en Cretas, Teruel)". Caesaraugusta. Publicaciones del Seminario de Arqueología y Numismática Aragonesa, 9-10, pp. 133-136.

VALLESPÍ PÉREZ, Enrique. 1958a: “Sobre los conjuntos líticos de Torre Los Negros del Museo provincial de Teruel". Teruel, 20, pp. 121-143 y 12 láms.

VALLESPÍ PÉREZ, Enrique. 1958b: "Prospecciones arqueológicas en Maella”. Caesaraugusta. Publicaciones del Seminario de Arqueología y Numismática Aragonesa, 11-12, pp. 33-38.

VALLESPÍ PÉREZ, Enrique. 1959: "Bases arqueológicas para el estudio de los talleres de sílex del Bajo Aragón. Hacia una seriación de las industrias líticas postpaleolíticas bajoaragonesas”. Caesaraugusta. Publicaciones del Seminario de Arqueología y Numismática Aragonesa, 13-14, pp. 7-19.

VALLESPÍ PÉREZ, Enrique. 1960a. "Excavaciones en los yacimientos líticos de ‘El Sol de la Piñera’ y 'El Serdá' en Fabara (Zaragoza). Memoria de la I Campaña”. Caesaraugusta. Publicaciones del Seminario de Arqueología y Numismática Aragonesa, 15-16, pp. 19-39.

VALLESPÍ PÉREZ, Enrique. 1960b: "Las industrias líticas de la Sierra de Camero Nuevo (Logroño)". Berceo, 54-55, pp. 1-41.

VALLESPÍ PÉREZ, Enrique. 1961a: "Revisión metodológica del problema del Paleolítico del Bajo Aragón". Caesaraugusta. Publicaciones del Seminario de Arqueología y Numismática Aragonesa, 17-18, pp. 19-63. VALLESPÍ PÉREZ, Enrique. 1961b: "Síntesis del estado actual del conocimiento de las industrias macrolíticas postpaleolíticas del cuadrante Nordeste de España". VI Congreso Nacional de Arqueología. Oviedo 1959, pp. 64-70. Zaragoza.

VALLESPÍ PÉREZ, Enrique. 1961c: "Sobre la problemática del Bronce Final y el asentamiento hallstáttico en el Bajó Aragón: El substrato indígena recipendiario de los inmigrantes". Teruel, 26, pp. 245-259.

VALLESPÍ PÉREZ, Enrique. 1966: "Las investigaciones prehistóricas en la provincia de Álava”. Estudios de Arqueología Alavesa, 1, pp. 7-26.

VALLESPÍ PÉREZ, Enrique. 1967: “Talleres de sílex al aire libre en Álava”. Ampurias, XXIX, pp 231-234.

VALLESPÍ PÉREZ, Enrique. 1968: “Talleres de sílex al aire libre en el País Vasco meridional”. Estudios de Arqueología Alavesa, III, pp. 7-27.

VALLESPÍ PÉREZ, Enrique. 1970: "Arqueología y arqueólogos alaveses. El momento actual de la investigación arqueológica en la provincia de Álava”. Estudios de Arqueología Alavesa, IV, pp. 7-41.

VALLESPÍ PÉREZ, Enrique, 1972a: “Conjuntos líticos de superficie, del Museo Arqueológico de Álava”. Estudios de Arqueología Alavesa, V, p. 7-79.

VALLESPÍ PÉREZ, Enrique. 1972b: “Hipótesis de trabajo sobre el sustrato arqueológico de la romanizacion del País Vasco Meridional (Álava y Navarra)”. Estudios de Deusto, XX 46, p. 241-250.

VALLESPÍ PÉREZ, Enrique. 1973: “Excursión arqueológica por el río Najerilla”. Miscelánea de Arqueología Riojana, pp. 65-71. Instituto de Estudios Riojanos. Logroño.

VALLESPÍ PÉREZ, Enrique. 1974a: "Yacimientos de superficie de la Edad de Bronce en Navarra". Cuadernos de Trabajos de Historia, 2, pp. 23-73.

VALLESPÍ PÉREZ, Enrique. 1974b: “Hallazgos líticos sueltos de Álava, Navarra y Logroño". Estudios de Arqueología Alavesa, VI, pp. 57-65.

VALLESPÍ PÉREZ, Enrique. 1975: “Investigación de la Prehistoria Navarra”. Príncipe de Viana, 138-139, pp. 47-81.

VALLESPÍ PÉREZ, Enrique. 1983: “El poblamiento paleolítico inicial”. En Sevilla y su provincia. Tomo 2, pp. 15-21. Editorial Gever. Sevilla

VALLESPÍ PÉREZ, Enrique. 1985a: "La primera ocupación del espacio local de Sevilla”. Archivo Hispalen- 
se, 209, pp. 67-75.

VALLESPÍ PÉREZ, Enrique. 1985 b: "Un bifaz achelense del tramo subbético exterior occidental (Los Corrales, Sevilla)". Anuario Arqueológico de Andalucía. Tomo III. Actividades de Urgencia, pp. 188-289. Junta de Andalucía. Sevilla

VALLESPÍ PÉREZ, Enrique. 1986a: “Piezas líticas y talleres domésticos en los poblados 'hallstátticos' del Bajo Aragón”. En Segundos encuentros de Prehistoria Aragonesa. Bajo Aragón Prehistoria, IX-X, pp. 71-81. Centro de estudios comarcales Bajo Aragón. Caspe.

VALLESPÍ PÉREZ, Enrique. 1986b: "El Paleolítico Inferior y Medio en Andalucía". En Homenaje a Luis Siret (1934-1984), pp. 59-66. Consejería de Cultura. Junta de Andalucía. Sevilla.

VALLESPÍ PÉREZ, Enrique. 1986c: “Cultura de las graveras y comienzos del Achelense Ibérico". En Estudios en Homenaje al Dr. Antonio Beltrán, pp. 149-157. Universidad de Zaragaza. Zaragoza.

VALLESPÍ PÉREZ, Enrique. 1987: “Sobre el Paleolítico Inferior Inicial de la Península Ibérica”. Veleia, 4, pp. 51-66.

VALLESPÍ PÉREZ, Enrique. 1988: “Paleolítico Medio de aspecto postachelense en la depresión inferior del Guadalquivir". Espacio, Tiempo y Forma. Serie I. Prehistoria I. Homenaje al profesor Eduardo Ripoll Perelló, pp. 85-91.

VALLESPÍ PÉREZ, Enrique. 1992: “Las industrias achelenses de Andalucía: Ordenación y comentarios”. Spal, 1, pp. 61-78.

VALLESPÍ PÉREZ, Enrique. 1993. “Sobre un bifaz cordiforme del Bajo Genil”. Spal, 2, pp. 329-332.

VALLESPÍ PÉREZ, Enrique. 1994: "El Bajo Guadalquivir en el Paleolítico Inferior y Medio peninsular". Homenaje al Dr. Joaquín González Echegaray. Museo y Centro de Investigación de Altamira. Monografía 17. Ministerio de Cultura, pp. 61-78. Santander.

VALLESPÍ PÉREZ, Enrique. 1999: “Comentario al Paleolítico Ibérico: continuidad, etapas y perduraciones del proceso tecnocultural”. Spal, 8, pp. 39-46.

VALLESPÍ PÉREZ, Enrique. 1995: “I. Paleolítico y Epipaleolítico”. En E. RIPOLL y M.A. LADERO (eds.): Actas del II Congreso Internacional "El Estrecho de Gibraltar", pp. 4-18. UNED y Ayuntamiento de Ceuta. Madrid.

VALLESPÍ PÉREZ, Enrique. 2001a: “Reconocimiento arqueológico del Bajo Aragón en el siglo XIX y primer tercio del XX: evocación de sus protagonistas". Spal, 10, pp. 59-73.

VALLESPÍ PÉREZ, Enrique. 2001b: “Pleistoceno Inferior y Medio. Paleolítico Inferior”. En J.C. MARTíN DE LA CRUZ, M.D. ASQUERINO; J.L. SANCHIDRIÁN y E. VALLESPÍ: Orientación de la investigación en la Pre y Protohistoria de Andalucía según el I y II Congreso de Historia de Andalucía. En: Actas del III Congreso de Historia de Andalucía, pp. 19-20. Cajasur. Córdoba.

VALLESPÍ PÉREZ, Enrique. 2006a: "Sobre el descubrimiento de las pinturas levantinas: Los testimonios de los tres protagonistas del Calapatá (S. Vidiella, H. Breuil y J. Cabré en 1906-1909)". Cuadernos de Arqueología Universidad de Navarra, 14, pp. 59-68.

VALLESPÍ PÉREZ, Enrique. 2006b: "El Bajo Guadalquivir en los comienzos de su historia humana. Investigaciones del proyecto 1985-1993 y tesis doctorales de 1993, 98 y 99 (nota informativa)”. Carel, 4, pp. 141-1422.

VALLESPÍ PÉREZ, Enrique. 2007: “Sobre la incorporación a la historia humana del espacio local de Sevilla”. En P. BOLAÑOS; A. DOMÍNGUEZ y M. DE LOS REYES (coord.): Homenaje al profesor Klaus Wagner: geh hin und lerne. Vol. 2, pp. 843-849. Universidad de Sevilla. Sevilla.

VALLESPÍ PÉREZ, Enrique. 2007-2008: "Meditación de unos apuntes de curso y del nacimiento de una escuela de prehistoriadores". Veleia, 24-25, pp. 73-93.

VALLESPÍ PÉREZ, Enrique. 2010: El grupo del Boletín de Historia y Geografía del Bajo Aragón. Evocación en su correspondencia epistolar (1883-1954). Caesaraugusta, 81. Institución Fernando El Católico. Excma. Diputación de Zaragoza. Zaragoza.

VALLESPÍ PÉREZ, Enrique; RUIZ DE GAONA, Máximo. 1971: "Piezas inéditas de tradición achelense en las series líticas de Coscobilo de Olazagutía (Navarra)". Munibe, XXIII 2/3, pp. 375-384.

VALLESPÍ PÉREZ, Enrique; MOYA VALGAÑóN, José Gabriel 1973: “Talleres de sílex en la Rioja Alta, términos de Sajazarra y Fonzaleche". Miscelánea de Arqueología Riojana, pp. 53-64. Instituto de Estudios Riojanos. Logroño.

VALLESPÍ PÉREZ, Enrique; CIUDAD SERRANO, Antonio; GARCÍA SERRANO, Rafael. 1979: Achelense y

Revista Atlántica-Mediterránea de Prehistoria y Arqueología Social 23, pp. 12-31

Universidad de Cádiz 


\section{NECROLÓGICAS}

Musteriense de Porzuna (Ciudad Real). Materiales de superficie, I (Colección E. Oliver). Museo de Ciudad Real. Colección Estudios y Monografías 1. Ciudad Real.

VALLESPÍ PÉREZ, Enrique; CABRERO GARCÍA, Rosario. 1980-1981: "Calcolítico y Bronce Pleno en el Moral de Montecorto (Ronda) (Colección Pérez Aguilar)”. Mainake, II-III, 48-75.

VALLESPÍ PÉREZ, Enrique; DEL AMO Y DE LA HERA, Mariano; ÁLVAREZ GARCÍA, Genaro. 1981: "Primeras evidencias paleolíticas de la provincia de Huelva". Huelva Arqueológica, V, pp. 9-28.

VALLESPÍ PÉREZ, Enrique; ÁLVAREZ GARCÍA, Genaro; AMORES CARREDANO, Fernando; ESCACENA CARRASCO, José Luis. 1982: "Complejos de cantos tallados y bifaces en el Bajo Guadalquivir. Perspectivas de su estudio". Grupo Español de Trabajos del Cuaternario. 5ํㅡ Reunion, pp. 79-94. Universidad de Sevilla. Sevilla.

VALLESPÍ PÉREZ, Enrique; DÍAZ DEL OLMO, Fernando; ÁLVAREZ GARCÍA, Genaro. 1983-1984: “Cantos tallados en la terraza baja del Guadalete, Sector Villamartín (Cádiz)”. Boletín del Museo de Cádiz, IV, pp. 5-28.

VALLESPÍ PÉREZ, Enrique; HURTADO PÉREZ, Víctor; CALDERÓN, Tomás. 1985a: "La industria lítica tallada de superficie de la Pijotilla (Badajoz)". Series de Arqueología Extremeña, no 1, pp. 11-63. Cáceres. VALLESPÍ PÉREZ, Enrique; CIUDAD SERRANO, Antonio; HURTADO PÉREZ, Víctor; GARCÍA SERRANO, Rafael; CABALLERO KLINK, Antonio. 1985b: Materiales del Neolítico Final-Eneolítico de la Vega de Los Morales (Aldea del Rey, Ciudad Real). Museo de Ciudad Real. Estudios y Monografías 15. Ciudad Real. VALLESPÍ PÉREZ, Enrique; CIUDAD SERRANO, Antonio; GARCÍA SERRANO, Rafael. 1985c: Achelense y Musteriense de Porzuna (Ciudad Real). Materiales de superficie, II (Muestra de las Colecciones de A. Retamosa y M. Expósito). Universidad de Castilla La Mancha. Ciudad Real.

VALLESPÍ PÉREZ, Enrique; CIUDAD SERRANO, Antonio; GARCÍA SERRANO, Rafael; CABALLERO KLINK, Antonio. 1985d: "Industrias líticas talladas del Eneolítico y Bronce en la provincia de Ciudad Real". Oretum, 1, pp. 81-127.

VALLESPÍ PÉREZ, Enrique; ÁLVAREZ GARCÍA, Genaro; PEREZ SINDREU, Francisco de Paula; RUFETE TOMICO, Pilar. 1986: "Nuevas atribuciones onubenses al paleolítico inferior y medio". Huelva en su Historia, 1, pp. 43-56.

VALLESPÍ PÉREZ, Enrique; CIUDAD SERRANO, Antonio; GARCÍA SERRANO, Rafael. 1988a: "Orígenes del poblamiento en Castilla-La Mancha". En I Congreso de historia de Castilla-La Mancha. Pueblos y culturas prehistóricas y protohistóricas vol. 2 (I), pp. 7-16. Junta de Comunidades de Castilla y León. Toledo.

VALLESPÍ PÉREZ, Enrique; RAMOS MUÑOZ, José; MARTÍN CÓRDOBA, Emilio; ESPEJO HERRERÍAS, María del Mar; CANTALEJO DUARTE, Pedro. 1988b: "Talleres líticos andaluces del Calcolítico y Bronce". Revista de Arqueología, 90, pp. 14-24.

VALLESPÍ PÉREZ, Enrique; RAMOS MUÑOZ, José; CANTALEJO DUARTE, Pedro; ESPEJO HERRERÍAS, María del Mar; MARTÍN CÓRDOBA, Emilio. 1988c: "Picos campiñenses del tramo Subbético de Málaga relacionables con el Norte de África”. En Congreso Internacional 'El Estrecho de Gibraltar', pp. 271-284. Ceuta. 1987. UNED.

VALLESPÍ PÉREZ, Enrique; DÍAZ DEL OMO, Fernando; ÁLVAREZ GARCÍA, Genaro; VALLESPÍ GARCÍA, Enrique. 1988d: “Secuencia paleolítica del bajo Guadalquivir". Revista de Arqueología, 82, pp. 8-17.

VALLESPÍ PÉREZ, Enrique; CIUDAD SERRANO, Antonio; GARCÍA SERRANO, Rafael. 1989a: "Eneolítico y Bronce en la Mesa de Ocaña (Mancha toledana): materiales líticos de la colección P. Jesús Santos, O.P.”. Cuadernos de Estudios Manchegos, 19, pp. 79-111.

VALLESPÍ PÉREZ, Enrique; RAMOS MUÑOZ, José; MARTÍN CÓRDOBA, Emilio. 1989b: “Bifaz del Alto Vélez, del Achelense Superior o de su tradición inmediata”. Mainake, XI-XII, pp. 5-10.

VALLESPÍ PÉREZ, Enrique; LOPEZ PAYER, Manuel; SORIA LERMA, Miguel. 1992: "Sobre los comienzos del poblamiento humano del Alto Guadalquivir". En Ias Jornadas del Alto Guadalquivir. La Prehistoria, pp. 25-31. Ayuntamiento de Quesada. Quesada, Jaén.

VALLESPÍ PÉREZ, Enrique; DÍAZ DEL OMO, Fernando. 1996: "Industries in quarzite and the beginning of the use of Flint in the Lower and Middle Palaeolithic Sequence of the Bajo Guadalquivir". En N. MOLONEY; L. RAPOSO y M. SANTONJA (eds.): Non Flint Stone tooles and the Palaeolithic Occupation of the Iberian Peninsula, pp. 135-140. BAR International Series 649. Oxford.

VALLESPÍ PÉREZ, Enrique; FERNÁNDEZ CARO, Juan José; CARO GÓMEZ, José Antonio. 2001: “La secuencia paleolítica de la Depresión bética inferior: Valles del Guadalquivir y Guadalete". En Actas del III 
Congreso de Historia de Andalucía, pp. 443-446. Cajasur. Córdoba.

VALLESPÍ PÉREZ, Enrique; FERNÁNDEZ CARO, Juan José; CARO GÓMEZ, José Antonio. 2007: "Las claves secuenciales del Paleolítico Inferior de Andalucía". Caesaraugusta, 78, pp. 69-72.

JOSÉ RAMOS MUÑOZ

Catedrático de Prehistoria. Universidad de Cádiz.

Revista Atlántica-Mediterránea de Prehistoria y Arqueología Social 23, pp. 12-31

Universidad de Cádiz 